\title{
Tuning of Reduced Graphene Oxide Thin Film as an Efficient Electron Conductive Interlayer in a Proven Heterojunction Photoanode for Solar-driven Photoelectrochemical Water Splitting
}

\author{
Chong Siang Yaw ${ }^{1}$, Wen Cai Ng${ }^{1}$, Qiushi Ruan², Junwang Tang ${ }^{2}$, Ai Kah Soh ${ }^{3}$, Meng Nan \\ Chong ${ }^{1,4^{*}}$
}

${ }^{1}$ School of Engineering, Chemical Engineering Discipline, Monash University Malaysia, Jalan Lagoon Selatan, Bandar Sunway, Selangor Darul Ehsan 47500, Malaysia

${ }^{2}$ Department of Chemical Engineering, University College London, Torrington Place, London WC1E 7JE, United Kingdom

${ }^{3}$ School of Engineering, Mechanical Engineering Discipline, Monash University Malaysia, Jalan Lagoon Selatan, Bandar Sunway, Selangor Darul Ehsan 47500, Malaysia

${ }^{4}$ Sustainable Water Alliance, Advanced Engineering Platform, Monash University Malaysia, Jalan Lagoon Selatan, Bandar Sunway, Selangor DE 47500, Malaysia

*Corresponding author:

Associate Professor Dr. Meng Nan Chong

School of Engineering, Chemical Engineering Discipline, Monash University

Malaysia, Jalan Lagoon Selatan, Bandar Sunway, Selangor DE 47500 Malaysia

Email: Chong.Meng.Nan@monash.edu 


\begin{abstract}
Although bismuth vanadate $\left(\mathrm{BiVO}_{4}\right)$ has shown excellent photoelectrochemical (PEC) properties and is a good candidate of photoanode materials, the solar-driven PEC water splitting performance is still remained below its full potential due to the fast recombination and sluggish charge mobility of photogenerated charge carriers. Previously, we have communicated a proven Type II staggered vanadium pentoxide $\left(\mathrm{V}_{2} \mathrm{O}_{5}\right) / \mathrm{BiVO}_{4}$ heterojunction photoanode that could improve the photocurrent density. This study aimed to examine the effect of introducing an rGO thin film as an efficient electron conductive interlayer in a proven $\mathrm{V}_{2} \mathrm{O}_{5} / \mathrm{BiVO}_{4}$ heterojunction photoanode, and subsequently tuning the rGO film thickness in achieving the optimum PEC performance. The resultant ternary photoanode structure of $\mathrm{V}_{2} \mathrm{O}_{5} / \mathrm{rGO} / \mathrm{BiVO}_{4}$ was characterised by using field emission-scanning electron microscopy (FE-SEM), high resolution-transmission electron microscopy (HR-TEM), UV-vis spectroscopy, X-ray diffractometer (XRD), Raman spectroscopy and photoluminescence (PL) measurements. Results showed that the interlayer rGO thin film arising from the sequential drop cast and electrochemical reduction of $320 \mu \mathrm{L}$ ultrasonicated GO solution resulted in the optimal photocurrent density of $2.1 \mathrm{~mA} / \mathrm{cm}^{2}$ at $1.5 \mathrm{~V}$ vs. $\mathrm{Ag} / \mathrm{AgCl}$. Furthermore, the chemical physics surrounding the photogenerated charge carrier transfer for heterojunction $\mathrm{V}_{2} \mathrm{O}_{5} / \mathrm{BiVO}_{4}$ was validated for the structure with and without the rGO interlayer. In particular, the electrochemical impedance spectroscopy (EIS) was used to measure multiple resistances at the FTO/semiconductor, semiconductor/semiconductor and semiconductor/electrolyte interfaces. Additionally, the charge transfer $\left(K_{t}\right)$ and recombination $\left(K_{r}\right)$ rate constants for the heterojunction $\mathrm{V}_{2} \mathrm{O}_{5} / \mathrm{BiVO}_{4}$ with the rGO interlayer were quantified using intensity modulated photocurrent spectroscopy (IMPS). Finally, the $\mathrm{PEC} \mathrm{H}_{2}$ evolution rate from the ternary $\mathrm{V}_{2} \mathrm{O}_{5} / \mathrm{rGO} / \mathrm{BiVO}_{4}$ photoanode was measured to be $32.7 \mu \mathrm{mol} / \mathrm{hr}$, which was about 3-fold higher than the bare $\mathrm{V}_{2} \mathrm{O}_{5} / \mathrm{BiVO}_{4}$ heterojunction photoanode.
\end{abstract}

Key words: $\mathrm{BiVO}_{4}$; heterojunction; reduced graphene oxide; solar hydrogen; photogenerated charge carriers 


\section{Introduction}

Since the beginning of $21^{\text {st }}$ century, the continuous and excessive use of non-renewable fossil fuels is the primary cause leading to a massive influx of carbon dioxide emission into the environment, and resulting in global warming and climate change issues [1,2]. Therefore, the exploitation and development of alternative and renewable green energy sources have become a long-standing challenge for mankind [3]. Among the green energy sources, solar energy is by far the largest exploitable energy resource [4]. Due to the intermittent nature of solar energy, however, various efforts have been attempted to convert solar energy into storable form of chemical energy [5]. Photoelectrochemical (PEC) water splitting is widely regarded as one of the most promising routes for converting solar to hydrogen $\left(\mathrm{H}_{2}\right)$ energy, and this sustainable and pollution-free process endows $\mathrm{H}_{2}$ energy with an incomparable advantage among other green energy production routes $[6,7]$. The concept of $\mathrm{PEC}$ water splitting for $\mathrm{H}_{2}$ production by using semiconductor photoelectrode was first demonstrated in 1972 by Fujishima and Honda [8]. In a typical PEC cell, photogenerated charge carriers will be produced when the energy of light photon absorbed by the semiconductor photoelectrode is greater than its corresponding band gap [9]. Thus, semiconductor photoelectrode plays a significant role in determining the solar light spectral utilisation range, generation and/or migration of photogenerated charge carriers, and photostability which all have a direct influence on the performance of PEC water splitting [10].

Among the semiconductors, bismuth vanadate $\left(\mathrm{BiVO}_{4}\right)$ is one of the well-known photoelectrode materials that has favourable and promising properties, such as relatively narrow band gap $(2.4-2.5 \mathrm{eV})$ that absorbs into the visible light spectral region, favorable conduction band $(\mathrm{CB})$ edge position near to the thermodynamic $\mathrm{H}_{2}$ evolution potential, and resistant to photoinduced corrosion in near neutral aqueous condition [11]. Although $\mathrm{BiVO}_{4}$ is a promising photoanode used for PEC water oxidation, the performance of a single-component $\mathrm{BiVO}_{4}$ photoanode is usually hindered by the low separation efficiency of photogenerated charge carriers, and high bulk and surface recombination due to the poor mobility of electron-hole pairs [12]. One of the strategies to improve the performance of PEC water oxidation in $\mathrm{BiVO}_{4}$ is through the fabrication of heterojunction photoanode using two or more semiconductors to create an interface region with electric potential gradients. Through the creation of this interfacial charged region, this will facilitate the efficient separation of photogenerated charge carriers, 
suppress their surface recombination, and leaving more majority charge carriers for redox reactions [13, 14]. Previously, we have communicated a proven Type II staggered vanadium pentoxide $\left(\mathrm{V}_{2} \mathrm{O}_{5}\right) / \mathrm{BiVO}_{4}$ heterojunction photoanode that achieved a significantly improved photocurrent density of $1.53 \mathrm{~mA} / \mathrm{cm}^{2}$ at $1.5 \mathrm{~V}$ vs $\mathrm{Ag} / \mathrm{AgCl}$. The improvement in photocurrent generation was attributed to the wider utilisation of solar spectrum, efficient separation of photogenerated charge carriers, as well as improved charge mobility [15].

Of recent, reduced graphene oxide (rGO) has gained immense research interests owing to its 2-D $\mathrm{sp}^{2}$-hybridised carbon structure that can act as a solid state electron mediator with excellent electrical conductivity, light transmission, carrier mobility and large surface area properties [16]. Previously, Tan et al. found that rGO with its multi-merit optical, structural and electronic properties was able to promote efficient interfacial charge transfer between semiconductors, provide more surface active sites for water oxidation reaction, and facilitate a better electrical contact with the base FTO substrate [17]. Another study by Zhao et al. postulated that the introduction of $\mathrm{rGO}$ in their self-powered PEC biosensor based $\mathrm{CdS} / \mathrm{rGO} / \mathrm{ZnO}$ nanowire array heterostructure improved the interfacial electron transfer and help in suppressing the recombination of photogenerated charge carriers [18]. Thus far, there is no previous study reported on the role of $\mathrm{rGO}$ as an effective solid electron mediator in a proven heterojunction structure for application in solar-driven PEC water splitting. This study aimed to examine the effect of introducing an $\mathrm{rGO}$ thin film as an efficient electron conductive interlayer in a proven $\mathrm{V}_{2} \mathrm{O}_{5} / \mathrm{BiVO}_{4}$ heterojunction photoanode, and subsequently tuning the rGO film thickness in achieving the optimum PEC performance. The resultant ternary photoanode structure of $\mathrm{V}_{2} \mathrm{O}_{5} / \mathrm{rGO} / \mathrm{BiVO}_{4}$ was characterised by using field emission-scanning electron microscopy (FESEM), high resolution-transmission electron microscopy (HR-TEM), UV-vis spectroscopy, Xray diffractometer (XRD), Raman spectroscopy and photoluminescence (PL) measurements. Furthermore, the chemical physics surrounding the photogenerated charge carrier transfer for heterojunction $\mathrm{V}_{2} \mathrm{O}_{5} / \mathrm{BiVO}_{4}$ was validated for the structure with and without the rGO interlayer. In particular, the electrochemical impedance spectroscopy (EIS) was used to measure multiple resistances at the FTO/semiconductor, semiconductor/semiconductor and semiconductor/electrolyte interfaces. Additionally, the charge transfer $\left(K_{t}\right)$ and recombination $\left(K_{r}\right)$ rate constants for the heterojunction $\mathrm{V}_{2} \mathrm{O}_{5} / \mathrm{BiVO}_{4}$ with the $\mathrm{rGO}$ interlayer were quantified using intensity modulated photocurrent spectroscopy (IMPS). Finally, the photocurrent 
generation potential and $\mathrm{H}_{2}$ production were also quantified in providing a rational basis for the use of $\mathrm{rGO}$ as an electron conductive interlayer in the future design of heterojunction photoanode.

\section{Experimental}

\subsection{Materials}

Bismuth nitrate pentahydrate $\left(\mathrm{Bi}\left(\mathrm{NO}_{3}\right)_{3} .5 \mathrm{H}_{2} \mathrm{O}\right)$ was purchased from $\mathrm{R} \& \mathrm{M}$ Chemicals, United Kingdom. Vanadium (IV) oxide sulfate hydrate $\left(\mathrm{VOSO}_{4}, 97 \%\right)$ was obtained from Sigma Aldrich, USA. Nitric acid $\left(\mathrm{HNO}_{3}, 69 \%\right)$ and anhydrous sodium acetate $\left(\mathrm{CH}_{3} \mathrm{COONa}\right)$ were obtained from Friendemann Schmidt Chemical, Germany; absolute ethanol $\left(\mathrm{C}_{2} \mathrm{H}_{6} \mathrm{O}\right)$, hydrogen peroxide $\left(\mathrm{H}_{2} \mathrm{O}_{2}\right)(30 \mathrm{wt} \%)$, sulfuric acid $\left(\mathrm{H}_{2} \mathrm{SO}_{4}\right)(96 \mathrm{wt} \%)$, phosphoric acid $\left(\mathrm{H}_{3} \mathrm{PO}_{4}\right)(75 \mathrm{wt} \%)$, potassium permanganate $\left(\mathrm{KMnO}_{4}\right)$, hydrochloric acid $(\mathrm{HCl})(30 \mathrm{wt} \%)$, graphite powder and sodium sulfate $\left(\mathrm{Na}_{2} \mathrm{SO}_{4}\right)$ were purchased from Merck, Germany. FTO glass was purchased from Kaivo Optoelectronic Technology, China. The FTO glass substrate (14 $\Omega /$ sq) was cut into pieces with a working area of $3.33 \mathrm{~cm}^{2}$, and cleaned using acetone, ethanol and deionised water in an ultrasonic bath for $20 \mathrm{~min}$. All the reagents were of analytical grade and used without further purification.

\subsection{Synthesis of GO-coated FTO substrate}

GO powder was prepared through the oxidation of natural graphite powder by following the Improved Hummers' method [19]. Specifically, $3 \mathrm{~g}$ of graphite powder and $18 \mathrm{~g}$ of $\mathrm{KMnO}_{4}$ were added into a $400 \mathrm{~mL}$ mixture of concentrated $\mathrm{H}_{2} \mathrm{SO}_{4}$ and $\mathrm{H}_{3} \mathrm{PO}_{4}$ in a 9:1 volume ratio under an ice bath condition. The resultant mixture was heated to $65{ }^{\circ} \mathrm{C}$, and continuously stirred at 250 rpm for $72 \mathrm{hr}$. After the mixture was cooled down to room temperature, $3 \mathrm{~mL}$ of $30 \% \mathrm{H}_{2} \mathrm{O}_{2}$ was added into the mixture. This will result in the formation of dark precipitates, where they were then separated by using centrifugation at $4000 \mathrm{rpm}$ for $4 \mathrm{hr}$ followed by repetitive washing with ethanol, $\mathrm{HCl}$ and deionised water to remove the unexfoliated graphite. After that, the recovered dark solid precipitates were coagulated by adding ether and they were dried overnight at room 
temperature to obtain the final GO powder. Following this, the GO powder was used to prepare the GO-dispersion intended for GO-coated FTO glass substrate. Specifically, $0.5 \mathrm{mg} / \mathrm{mL}$ of GO powder was used in the preparation of GO-dispersion and the dispersion was allowed for ultrasonication for $1 \mathrm{hr}$. Thereafter, $240 \mu \mathrm{L}$ of the ultrasonicated GO dispersion was drop-casted onto the cleaned FTO glass substrate and dried at $60{ }^{\circ} \mathrm{C}$ to form the GO-coated FTO substrate. It was known that the use of GO-coated FTO substrate will provide better surface adhesion and support for the subsequent synthesis of multiple thin films of nanostructured materials than its bare FTO predecessor [20].Throughout this study, FTO substrate is referred to the GO-coated FTO substrate for simplicity of elaboration.

\subsection{Synthesis of $\mathrm{V}_{2} \mathrm{O}_{5} / \mathrm{BiVO}_{4}$ with $\mathrm{rGO}$ interlayer}

A thin film of $\mathrm{V}_{2} \mathrm{O}_{5}$ was electrodeposited onto the FTO substrate by applying a single anodic bias of $1.5 \mathrm{~V}$ vs $\mathrm{Ag} / \mathrm{AgCl}(3 \mathrm{M})$ for $10 \mathrm{~min}$ in a precursor solution that consists of $0.2 \mathrm{M} \mathrm{VOSO}_{4}$ and $20 \mathrm{~mL}$ of absolute ethanol. The $\mathrm{pH}$ of the electrolyte was adjusted to $\mathrm{pH} 1.8$ by adding a few drops of $95-99 \% \mathrm{H}_{2} \mathrm{SO}_{4}$. Subsequently, the $\mathrm{V}_{2} \mathrm{O}_{5}$ thin film was annealed at $400{ }^{\circ} \mathrm{C}$ for $1 \mathrm{hr}$ under air environment. After that, the rGO interlayer was introduced via the drop-cast of different volumes of ultrasonicated GO solution (i.e. 160, 240, 320 to $400 \mu \mathrm{L}$ ) on top of the annealed $\mathrm{V}_{2} \mathrm{O}_{5}$ thin film and abbreviated as $\mathrm{V}_{2} \mathrm{O}_{5} / \mathrm{i}-\mathrm{rGO}(\mathrm{i}=2-5)$. The electrochemical reduction of GO to rGO thin film was performed in $0.5 \mathrm{M} \mathrm{Na}_{2} \mathrm{SO}_{4}$ electrolyte for -1.5 to $0.5 \mathrm{~V}$ vs $\mathrm{Ag} / \mathrm{AgCl}$ with a scan rate of $0.05 \mathrm{~V} / \mathrm{s}$ for 4 cycles. Finally, the $\mathrm{BiVO}_{4}$ thin film was electrodeposited on top of the rGO interlayer from a precursor solution containing $\mathrm{Bi}\left(\mathrm{NO}_{3}\right)_{3}$ and $\mathrm{VOSO}_{4}$. For the preparation of $\mathrm{BiVO}_{4}$ precursor solution, $10 \mathrm{mM} \mathrm{Bi}\left(\mathrm{NO}_{3}\right)_{3}$ and $35 \mathrm{mM} \mathrm{VOSO}_{4}$ were dissolved in $0.5 \mathrm{M} \mathrm{HNO}_{3}$. Thereafter, $2 \mathrm{M}$ sodium acetate solution was used to adjust the $\mathrm{pH}$ of electrolyte to $\mathrm{pH} 5.1$ and continuously stirred for another $10 \mathrm{~min}$. The final $\mathrm{pH}$ of the mixture was adjusted to $\mathrm{pH} 4.7$ using $69 \% \mathrm{HNO}_{3}$. The electrodeposition synthesis of $\mathrm{BiVO}_{4}$ thin film was conducted potentiostatically with an applied potential of $1.9 \mathrm{~V}$ versus $\mathrm{Ag} / \mathrm{AgCl}$ for $45 \mathrm{~min}$. After the electrodeposition synthesis process, the as-deposited $\mathrm{BiVO}_{4}$ film was washed with deionised water to remove the presence of any ions followed by annealing treatment at $400{ }^{\circ} \mathrm{C}$ for $1 \mathrm{hr}$. Fig. 1 illustrates the step-by-step synthesis procedures of heterojunction photoanode of $\mathrm{V}_{2} \mathrm{O}_{5} / \mathrm{BiVO}_{4}$ with rGO interlayer. 


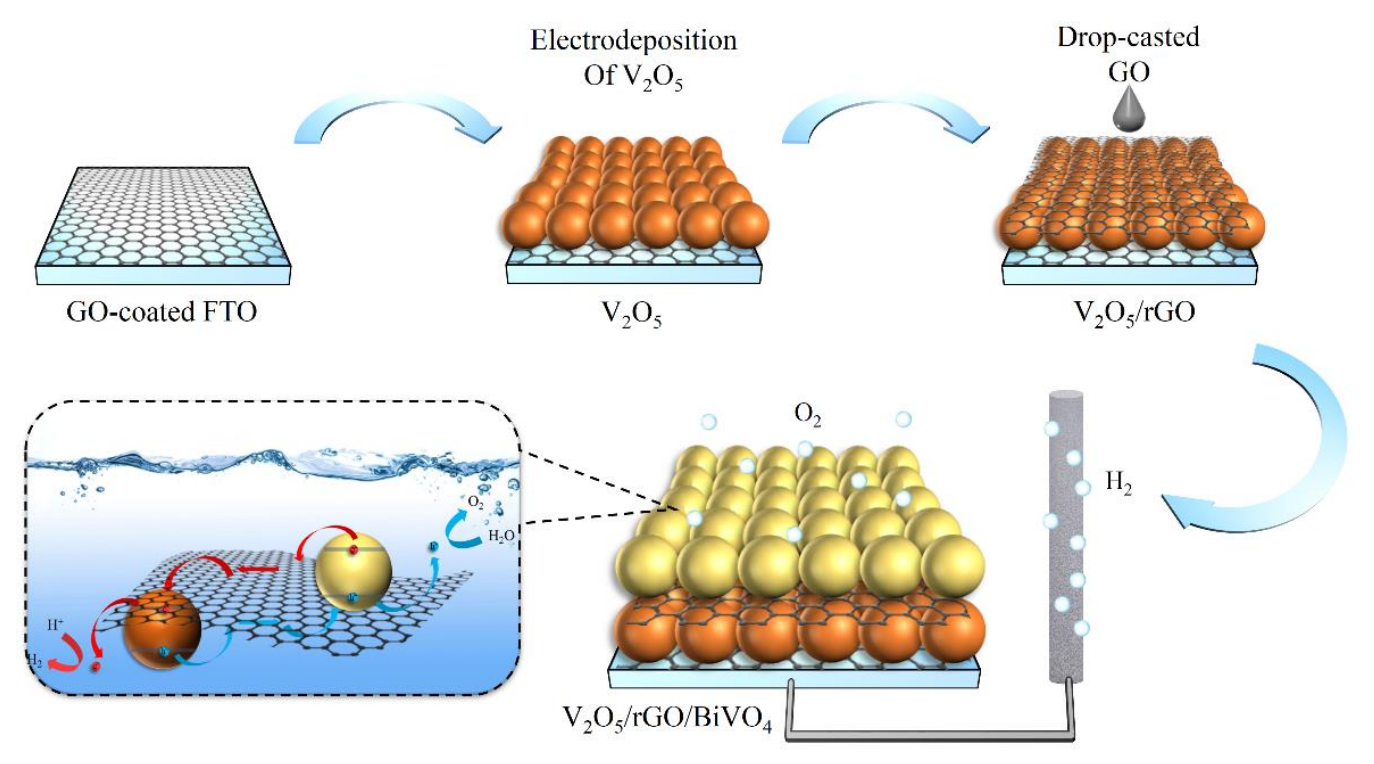

Fig. 1. Schematic illustration of the synthesis procedures of $\mathrm{V}_{2} \mathrm{O}_{5} / \mathrm{BiVO}_{4}$ with $\mathrm{rGO}$ interlayer.

\subsection{Characterisation}

PEC measurements of the as-prepared thin films on FTO substrates were carried out using a standard three-electrode assembly connected to an applied potentiostat/galvanostat (Metrohm PGSTAT 204 model, Netherlands). The reference and counter electrodes used were saturated $\mathrm{Ag} / \mathrm{AgCl}$ (3 M) electrode and Pt rod, respectively. Linear sweep voltammetry (LSV) scans under dark and visible light irradiation were recorded. A $150 \mathrm{~W}$ Xenon light with an output intensity of $100 \mathrm{~mW} / \mathrm{cm}^{2}$ was used as the irradiation source. All the LSV scans were conducted in a $0.5 \mathrm{M}$ aqueous $\mathrm{Na}_{2} \mathrm{SO}_{4}$ solution. EIS was performed at a frequency range of $100 \mathrm{kHz}-0.1 \mathrm{~Hz}$ at $1.2 \mathrm{~V}$ bias potential. IMPS measurements were conducted using a potentiostat (IVIUM technology) in a three-electrode configuration with a $\mathrm{Ag} / \mathrm{AgCl}(3 \mathrm{M} \mathrm{KCl})$ reference electrode and a $\mathrm{Pt}$ counter electrode. Modulated illumination (LED: cool white light) was provided by a ModuLight-module (IVIUM technology). A modulation depth of ca. $10 \%$ was used, and the frequency range was 10 kHz-0.1 Hz. Quantitative hydrogen yield measurements were performed and the $\mathrm{H}_{2}$ gas evolved was collected with an inverted and perfectly top-sealed syringe containing the $0.5 \mathrm{M} \mathrm{Na}_{2} \mathrm{SO}_{4}$ electrolyte. 
Surface morphology was examined using a Hitachi SU8010 FE-SEM. HR-TEM images were obtained using a JEOL JEM-2100F microscope operated at $200 \mathrm{kV}$ while the photoanode was prepared by TEM lamella preparation. The TEM lamella was prepared by focused ion beam (FIB) etching technique on a Strate 400s (SEI) with a gallium liquid metal ion source, a gas injection system and a micromanipulator (Omniprobe 200). UV-vis absorbance spectra were obtained using a spectrophotometer (Agilent, Cary 100) equipped with an integrated sphere The absorbance spectra were analysed under ambient temperature in the wavelength ranging from 200 to $800 \mathrm{~nm}$. The band gap energies of photoanodes were estimated by extrapolating the Tauc plot $[F(R) \cdot h v]^{1 / 2}$ to the abscissa of photon energy, $h v$. Meanwhile, the crystal structures were characterised by using an XRD (Bruker D8) employing a $\mathrm{Cu}-\mathrm{K} \alpha$ radiation with $40 \mathrm{kV}$ and 100 $\mathrm{mA}$ at $0.02^{\circ} \mathrm{s}^{-1}$ scan rate. Raman spectra were recorded using a Raman spectrometer (Horiba Scientific) with a solid state laser operating at an excitation source of $514 \mathrm{~nm}$. PL emission spectra were characterised using a Perkin Elmer LS55 spectrometer at an excitation wavelength of $325 \mathrm{~nm}$. Photoluminescence (PL) spectra were measured at room temperature using the fluorescence spectrometer (Perkin Elmer, LS55).

\section{Results and Discussion}

In this study, the $\mathrm{rGO}$ interlayer between $\mathrm{V}_{2} \mathrm{O}_{5}$ and $\mathrm{BiVO}_{4}$ thin films was electrochemically reduced from the controlled drop-casted GO solution via 4 cycles of cyclic voltammetry (CV) in removing the oxygen functionalities. Fig. 2 shows the $\mathrm{CV}$ diagram during the electrochemical reduction of $\mathrm{GO}$ on $\mathrm{V}_{2} \mathrm{O}_{5}$ thin film, where one anodic peak and two cathodic peaks (I and II) are observed. It can be seen that the reduction of current at negative potentials decreases considerably and disappeared after $4 \mathrm{CV}$ cycles. This shows that the exfoliated GO was electrochemically reduced with the applied potential, and the reduction of surface-oxygenated species on GO occurred irreversibly [19]. The final disappearance of peaks indicated that the electrochemical reduction of GO was completed. This can also be observed through the physical colour change of yellowish GO thin film to blackish rGO thin film. 


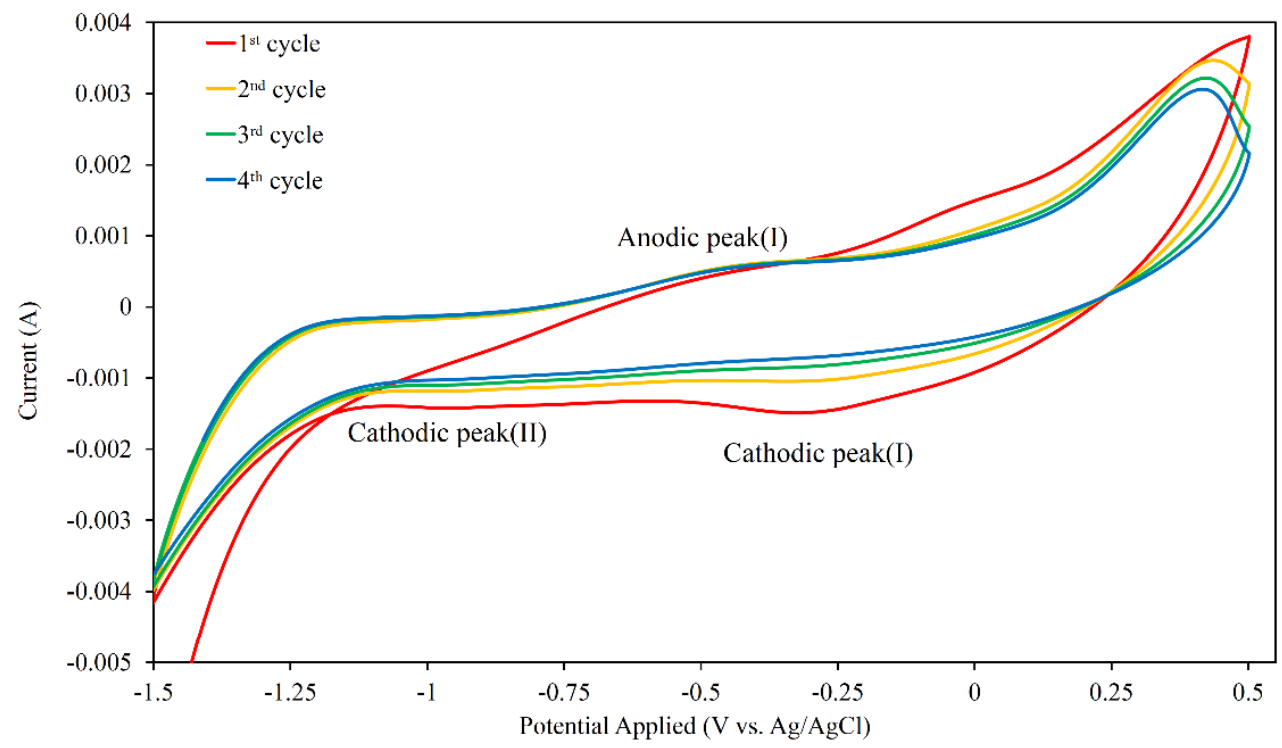

Fig. 2. $\mathrm{CV}$ diagram of electrochemical reduction of $\mathrm{GO}$ to form $\mathrm{rGO}$ interlayer on $\mathrm{V}_{2} \mathrm{O}_{5}$ thin film.

Fig. 3 shows the XRD patterns of a series of as-prepared thin film samples along with the information on their crystalline nature. The patterns were recorded with $2 \theta$ from 10 to $90^{\circ}$. It can be seen that all diffraction peaks exclusively correspond to the monoclinic clinobisvanite phase structure of $\mathrm{BiVO}_{4}$ (JCPDS No. 14-0688) and orthorhombic phase of $\mathrm{V}_{2} \mathrm{O}_{5}$ (JCPDS No. 72-433), along with the $\mathrm{GO}\left(12^{\circ}\right)$ and $\mathrm{SnO}_{2}\left(38,51,62\right.$ and $\left.66^{\circ}\right)$ peaks originating from the GO-coated FTO substrate [21]. The XRD patterns for $\mathrm{V}_{2} \mathrm{O}_{5} / \mathrm{BiVO}_{4}$ and $\mathrm{V}_{2} \mathrm{O}_{5} / \mathrm{rGO} / \mathrm{BiVO}_{4}$ shown that the crystal structure of $\mathrm{BiVO}_{4}$ was not affected during the surface modification process. However, the intensity of XRD peaks corresponding to the (001) and (110) peak of the $\mathrm{V}_{2} \mathrm{O}_{5}$ were reduced and totally disappeared after the introduction of an interlayer rGO in between $\mathrm{V}_{2} \mathrm{O}_{5}$ and $\mathrm{BiVO}_{4}$ thin films. These indicate that the crystallinity of $\mathrm{V}_{2} \mathrm{O}_{5}$ was affected during the electrochemical reduction of GO. However, there was no diffraction peak detected for rGO and this is due to the low content and fairly low diffraction intensity nature of rGO. 


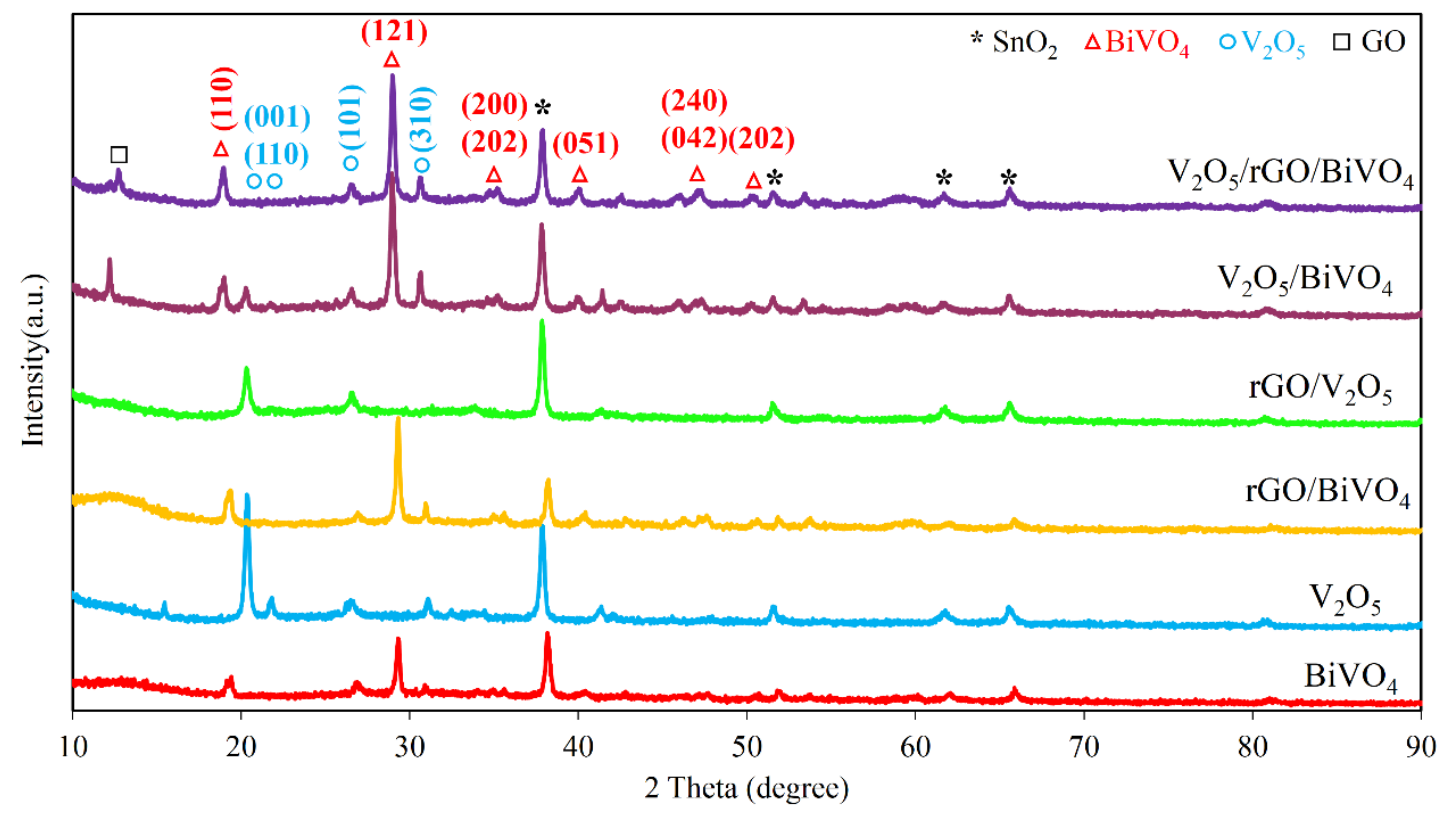

Fig. 3. XRD patterns of pristine $\mathrm{BiVO}_{4}$ and $\mathrm{V}_{2} \mathrm{O}_{5}, \mathrm{rGO}$ supported $\mathrm{BiVO}_{4}$ and $\mathrm{V}_{2} \mathrm{O}_{5}, \mathrm{~V}_{2} \mathrm{O}_{5} /$ $\mathrm{BiVO}_{4}$ as well as $\mathrm{V}_{2} \mathrm{O}_{5} / \mathrm{BiVO}_{4}$ and $\mathrm{V}_{2} \mathrm{O}_{5} / \mathrm{rGO} / \mathrm{BiVO}_{4}$ photoanodes.

In order to characterise the existence of rGO interlayer, Raman spectroscopy was used as well as to further distinguish the disorder in the crystal structures of GO and rGO. Fig. 4 shows the Raman characterisation on the electrochemical reduction of GO to rGO under different number of $\mathrm{CV}$ cycles. Two prominent peaks appeared in the Raman spectra of $\mathrm{GO}, \mathrm{V}_{2} \mathrm{O}_{5} / \mathrm{rGO}$ and $\mathrm{V}_{2} \mathrm{O}_{5} / \mathrm{rGO} / \mathrm{BiVO}_{4}$ photoanodes, and these peaks correspond to the $\mathrm{D}$ and G-bands of carbon materials [22]. The D-band peak is commonly ascribed to the breathing mode of aromatic rings (disordered $\mathrm{sp}^{3}$-bonded carbon), while the G-band is corresponded to the first-order scattering of the $\mathrm{E}_{2 \mathrm{~g}}$ phonons at the Brillouin zone center resulting from the bond stretching of $\mathrm{sp}^{2}$ carbon pairs in both rings and chains [23]. The intensity ratio of D and G-bands $\left(\frac{I_{D}}{I_{G}}\right)$ are generally accepted as the defect degree of graphitisation of carbonaceous materials and defect density, respectively. After the electrochemical reduction of GO, the intensities of the D and G-bands were increased. The intensity ratios increased from $0.87(0 \mathrm{CV})$ to $1.00(4 \mathrm{CV})$ with the increasing number of $\mathrm{CV}$ cycles and remained constant after $4 \mathrm{CV}$ cycles. Both the results and interpretation were consistent with the $\mathrm{CV}$ analysis, where they indicated that the electrochemical reduction of GO was completed. Furthermore, the position of the D-band was 
shifted from 1297 to $1292 \mathrm{~cm}^{-1}$ while the G-band was shifted from 1551 to $1546 \mathrm{~cm}^{-1}$. It was found that the intensity ratios Moreover, the intensity ratios for $\mathrm{V}_{2} \mathrm{O}_{5} / \mathrm{rGO}$ and $\mathrm{V}_{2} \mathrm{O}_{5} / \mathrm{rGO} / \mathrm{BiVO}_{4}$ were significantly increased when compared to GO. These signify a decrease in the average size of the $\mathrm{sp}^{2}$ domains of exfoliated GO upon the electrochemical reduction process. The relative changes in intensity ratio and intensity of the D-band confirms the formation of rGO, in addition to the potential creation of more defects in rGO that could increase the conductivity of the rGO thin film [24].

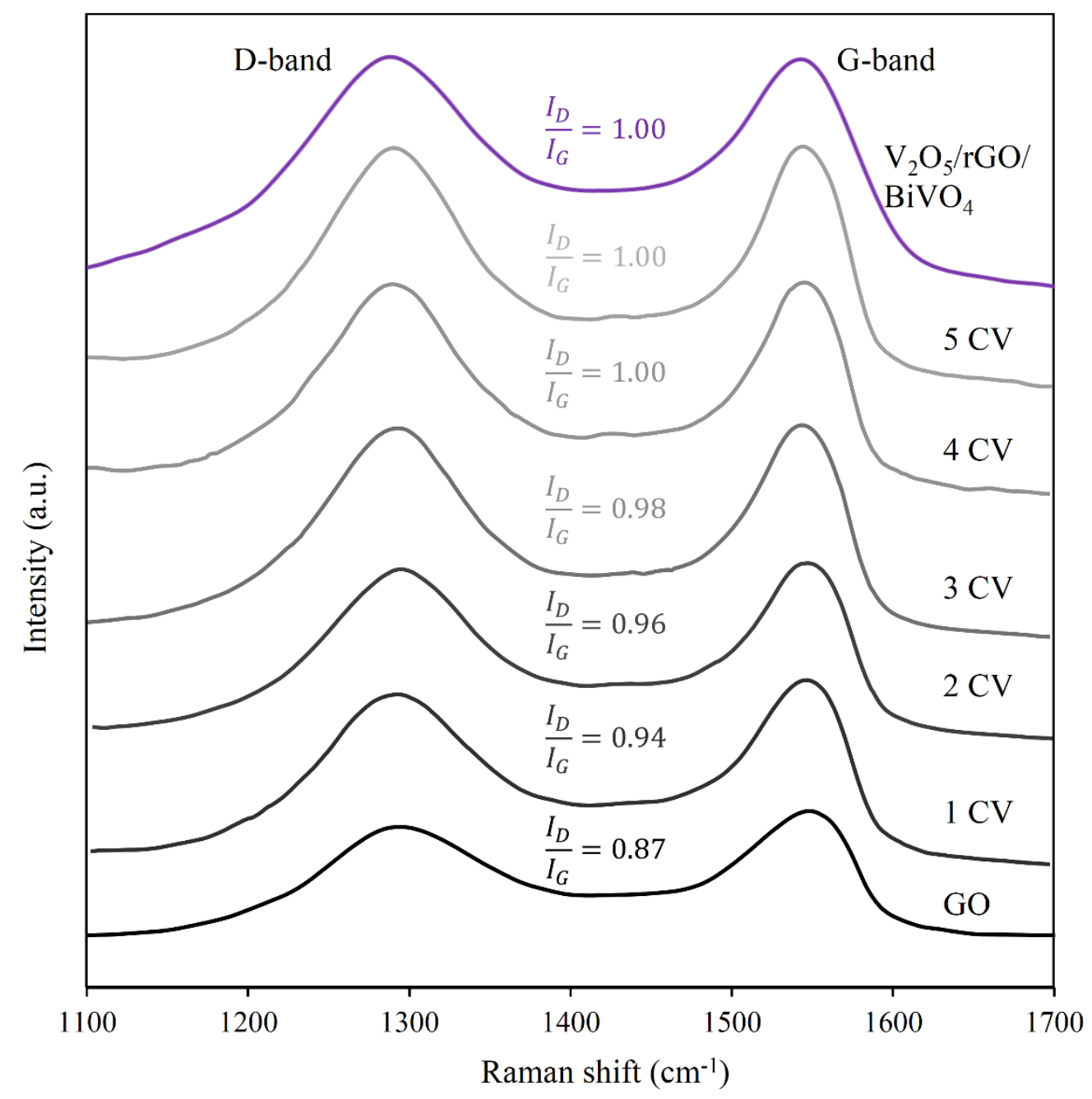

Fig. 4. Raman spectra of $\mathrm{V}_{2} \mathrm{O}_{5} / \mathrm{rGO}$ photoanodes with different number of cycles of $\mathrm{CV}$ and $\mathrm{V}_{2} \mathrm{O}_{5} / \mathrm{rGO} / \mathrm{BiVO}_{4}$ photoanode. 
The physicochemical states of $\mathrm{V}_{2} \mathrm{O}_{5} / \mathrm{rGO} / \mathrm{BiVO}_{4}$ photoanodes were analysed by using FE-SEM and are shown in Fig. 5. The existence of rGO interlayer underneath $\mathrm{BiVO}_{4}$ resulted in a better surface coverage by $\mathrm{BiVO}_{4}$, while the surface morphology of the ternary $\mathrm{V}_{2} \mathrm{O}_{5} / \mathrm{rGO} / \mathrm{BiVO}_{4}$ heterojunction photoanode become denser when compared to the pristine $\mathrm{V}_{2} \mathrm{O}_{5} / \mathrm{BiVO}_{4}$ photoanode. It was also observed that the surface morphology of the $\mathrm{V}_{2} \mathrm{O}_{5} / \mathrm{rGO} / \mathrm{BiVO}_{4}$ heterojunction photoanode contains more irregular nano-sized $\mathrm{BiVO}_{4}$ grains with the presence of rGO interlayer as opposed to the bare $\mathrm{V}_{2} \mathrm{O}_{5} / \mathrm{BiVO}_{4}$ heterojunction photoanode (without $\mathrm{rGO}$ interlayer). During the tuning of the rGO interlayer, it was observed that the nano-sized $\mathrm{BiVO}_{4}$ grains started to deglomerate and form necked nanoparticles with the increasing amount of dropcasted ultrasonicated GO solution. However, it reached a saturation point when $400 \mu \mathrm{L}$ ( $\mathrm{i}=5$ ) of ultrasonicated GO solution was drop-casted which was accompanied by the observation on the presence of $\mathrm{BiVO}_{4}$ thin film with slight physical cracks (Fig. 5f). The amount of drop-casted GO solution was tuned and found together with other electrochemical characterisations, the optimum volume amount was $320 \mu \mathrm{L}$. 

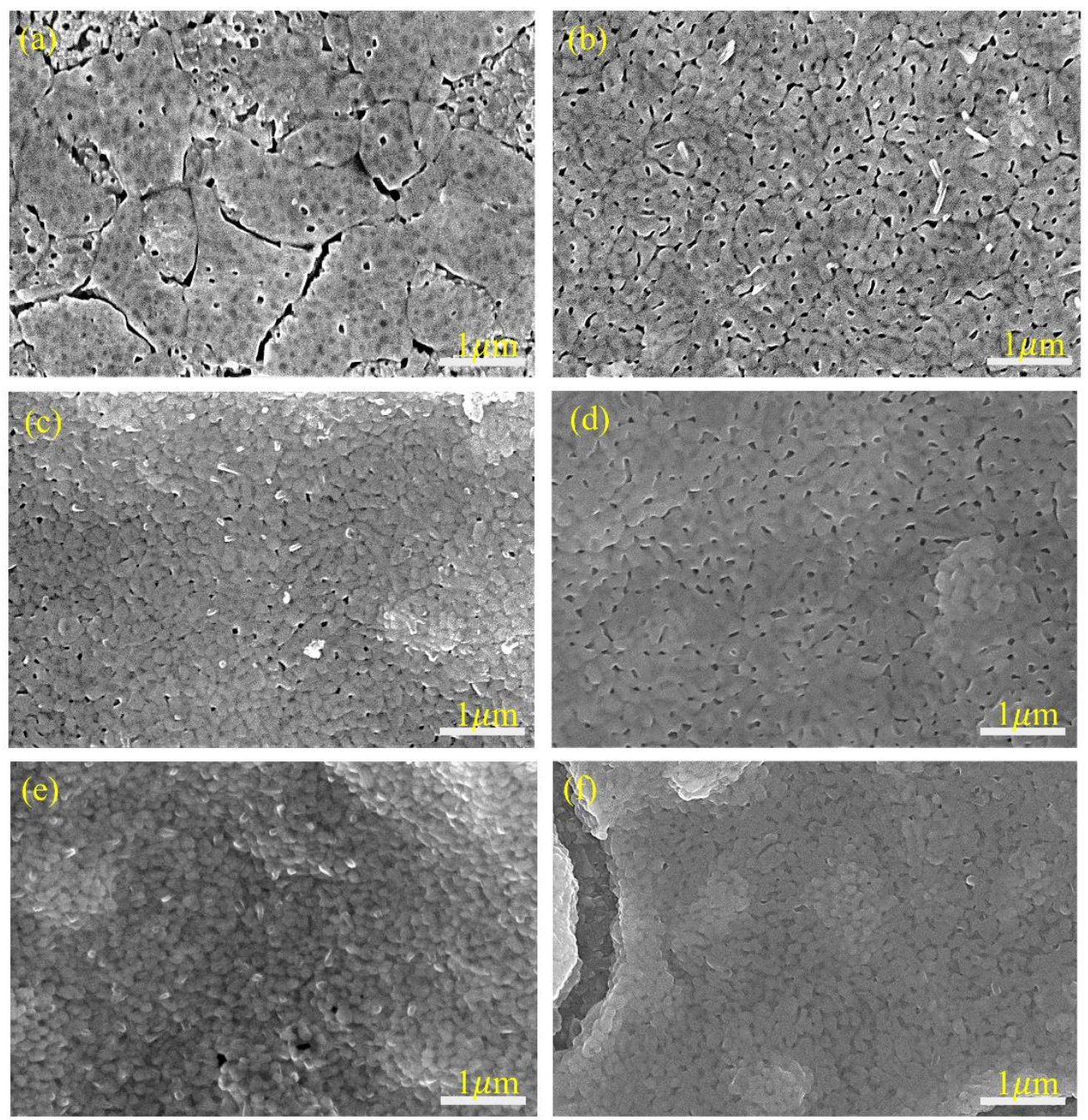

Fig. 5. FE-SEM images of (a) $\mathrm{BiVO}_{4}$, (b) $\mathrm{V}_{2} \mathrm{O}_{5} / \mathrm{BiVO}_{4}$, (c)-(f) $\mathrm{V}_{2} \mathrm{O} / \mathrm{i}-\mathrm{rGO} / \mathrm{BiVO}_{4}(\mathrm{i}=2-5$ ) photoanodes.

To obtain a deeper understanding of the morphological information in the $\mathrm{V}_{2} \mathrm{O}_{5} / \mathrm{BiVO}_{4}$ heterojunction photoanode with rGO interlayer and its interfacial structure, both the TEM and HR-TEM images were analysed. The cross-sectional TEM lamella of $\mathrm{V}_{2} \mathrm{O}_{5} / 4 \mathrm{rGO} / \mathrm{BiVO}_{4}$ film was prepared by FIB cutting and is shown in Fig. 6 (a). A layer of platinum cap was deposited on top of the $\mathrm{V}_{2} \mathrm{O}_{5} / 4 \mathrm{rGO} / \mathrm{BiVO}_{4}$ film to protect it from being damaged by the FIB cutting. Whilst the HR-TEM images in Fig. 6 (b) shows the interfaces of monoclinic clinobisvanite $\mathrm{BiVO}_{4}$, orthorhombic $\mathrm{V}_{2} \mathrm{O}_{5}$ and interlayer $\mathrm{rGO}$ together with their corresponding d-spacing. The lattice fringes of $0.308 \mathrm{~nm}$ and $0.207 \mathrm{~nm}$ shown in Fig. 6 (b) correspond to the spacing of (121) crystallographic plane of monoclinic clinobisvanite $\mathrm{BiVO}_{4}$ and (010) crystallographic plane of 
orthorhombic $\mathrm{V}_{2} \mathrm{O}_{5}$, respectively [25, 26]. Moreover, a clear amorphous structure of rGO interlayer was found in between $\mathrm{V}_{2} \mathrm{O}_{5}$ and $\mathrm{BiVO}_{4}$ films.
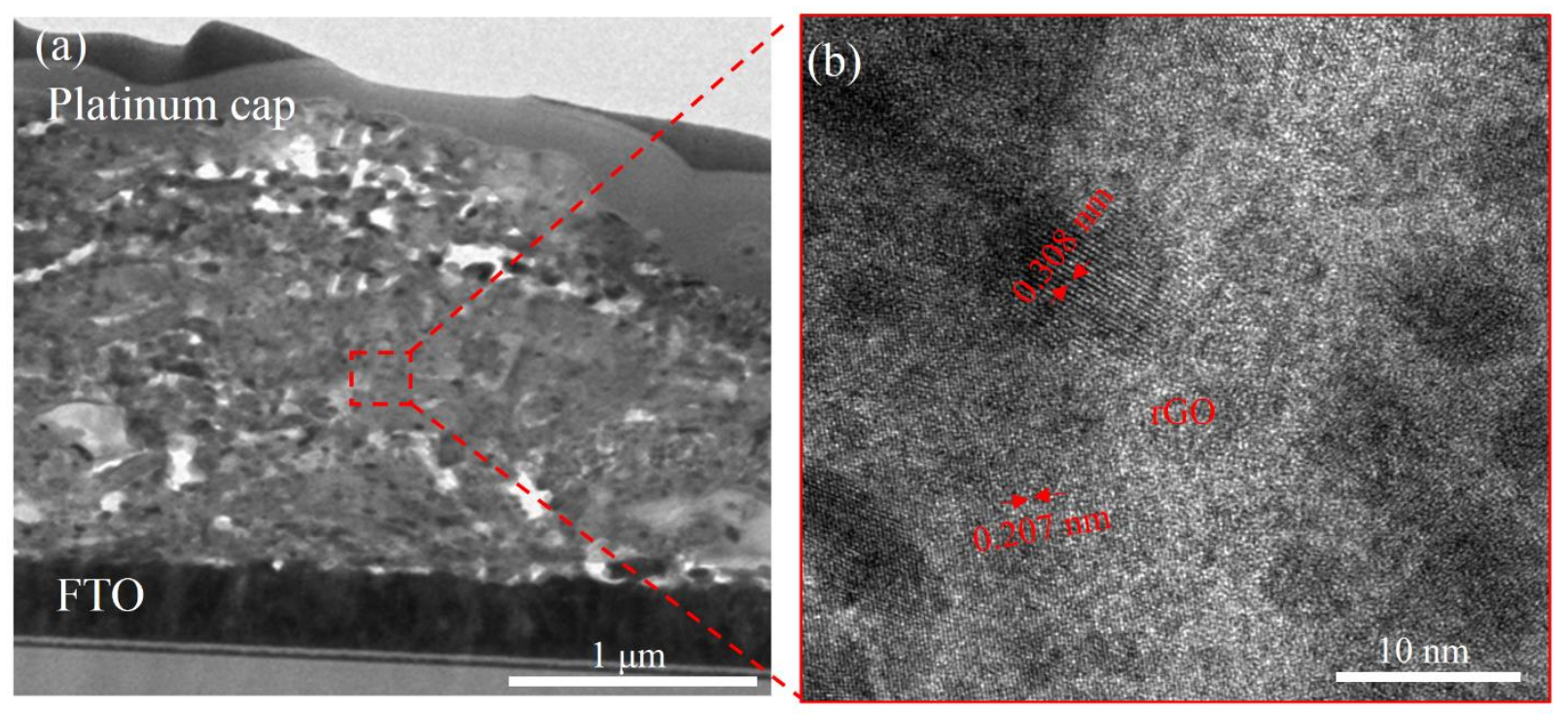

Fig. 6. (a) Cross-sectional TEM lamella and (b) HR-TEM images of the $\mathrm{V}_{2} \mathrm{O}_{5} / \mathrm{BiVO}_{4}$ heterojunction photoanode with rGO interlayer.

The band gap energies of $\mathrm{BiVO}_{4}$ and $\mathrm{V}_{2} \mathrm{O}_{5}$ were estimated to be $2.52 \mathrm{eV}$ and $2.44 \mathrm{eV}$, respectively, by plotting a Tauc plot as shown in Fig. 7 (a). The strong absorption peak obtained around $400-500 \mathrm{~nm}$ is corresponding to the charge-transfer transition involving the V-O component and the $\mathrm{Bi}$ and $\mathrm{V}$ centers [27]. In comparison to the individual pristine $\mathrm{BiVO}_{4}$ and $\mathrm{V}_{2} \mathrm{O}_{5}$, the $\mathrm{V}_{2} \mathrm{O}_{5} / \mathrm{BiVO}_{4}$ heterojunction photoanode was demonstrated to have a broadened light absorption range and improved light absorption intensities that enabled a stronger absorption ability of photons. Additionally, the light absorbance intensity was increased in the visible light region while a red shift of the absorption band edge was observed after the introduction of the rGO interlayer as shown in Fig. 7 (d). Such a phenomenon is attributed to the formation of chemical bonding ( $\mathrm{Bi}-\mathrm{C}$ and $\mathrm{V}-\mathrm{C}$ bond) between $\mathrm{BiVO}_{4}$ and $\mathrm{V}_{2} \mathrm{O}_{5}$ with specific sites of $\mathrm{rGO}$ that can form localised occupied state in the band gaps of $\mathrm{BiVO}_{4}$ and $\mathrm{V}_{2} \mathrm{O}_{5}$ [28]. By incorporating an $\mathrm{rGO}$ interlayer in the $\mathrm{V}_{2} \mathrm{O}_{5} / \mathrm{BiVO}_{4}$ heterojunction structure, it was observed that 
the light absorbance intensity increased in the visible light region and this was proportionate with the tunable amount of drop-casted rGO.
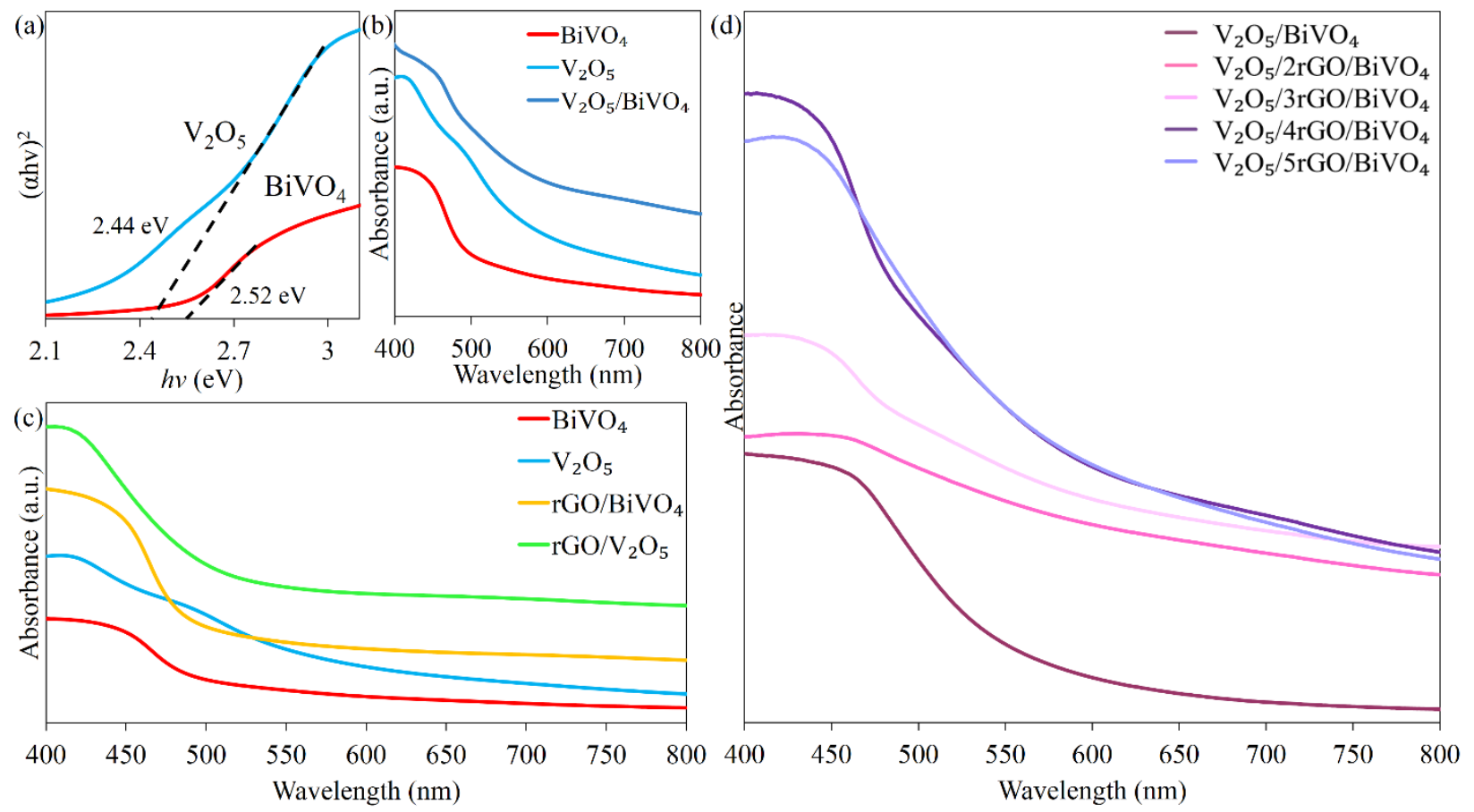

Fig. 7. (a) Tauc plot of pristine $\mathrm{BiVO}_{4}$ and $\mathrm{V}_{2} \mathrm{O}_{5}, \mathrm{UV}$-vis diffuse reflectance spectra of (b) $\mathrm{BiVO}_{4}, \mathrm{~V}_{2} \mathrm{O}_{5}$ and $\mathrm{V}_{2} \mathrm{O}_{5} / \mathrm{BiVO}_{4}$; (c) rGO supported $\mathrm{BiVO}_{4}$ and $\mathrm{V}_{2} \mathrm{O}_{5}$, (d) $\mathrm{V}_{2} \mathrm{O}_{5} / \mathrm{rGO} / \mathrm{BiVO}_{4}$ with different amount of drop-casted rGO.

In order to further examine the influence of $\mathrm{rGO}$ interlayer on the $\mathrm{V}_{2} \mathrm{O}_{5} / \mathrm{BiVO}_{4}$ photoanode, $\mathrm{PL}$ analysis was carried out to understand the degree of photogenerated charge transfer, trapping and separation in pristine $\mathrm{BiVO}_{4}$ (control), $\mathrm{V}_{2} \mathrm{O}_{5} / \mathrm{BiVO}_{4}$ (control) and $\mathrm{V}_{2} \mathrm{O}_{5} / \mathrm{rGO} / \mathrm{BiVO}$. A notable PL quenching effect is observed from Fig. 8 when the rGO interlayer was incorporated in the ternary structure of $\mathrm{V}_{2} \mathrm{O}_{5} / \mathrm{rGO} / \mathrm{BiVO}_{4}$. The intensity of $\mathrm{PL}$ spectrum indicates the recombination rate of photogenerated charge carriers, where a higher intensity implies a higher recombination rate as the order in the degree of PL quenching will in accordance with the PEC water splitting performance of the photoelectrode [29]. From Fig. 8, the luminescence peak at $483 \mathrm{~nm}$ corresponds to the recombination of photogenerated hole formed in the $\mathrm{O}_{2 p}$ orbitals of the VB with the photogenerated electron in the $V_{3 d}$ orbitals of the $C B$, while the emission at $534 \mathrm{~nm}$ is 
due to the crystalline defects [30]. As for the $\mathrm{V}_{2} \mathrm{O}_{5} / \mathrm{BiVO}_{4}$ heterojunction photoanode, the photogenerated electron on $\mathrm{CB}$ of $\mathrm{BiVO}_{4}$ will migrate to the $\mathrm{CB}$ of $\mathrm{V}_{2} \mathrm{O}_{5}$ through an internal electric gradient that exists at the interface between two semiconductor thin films. This resulted in the suppression of photogenerated charge carriers recombination across the heterojunction structure, and in the result of quenching of PL spectra. The intensity of the PL spectrum was further reduced after the incorporation of the $\mathrm{rGO}$ interlayer into the proven $\mathrm{V}_{2} \mathrm{O}_{5} / \mathrm{BiVO}_{4}$ heterojunction structure. This was due to the fact that two-dimensional (2-D) rGO interlayer offers excellent electrical conductivity, acting as a superior electron transporting bridge and thus favoring the injection efficiency of photogenerated charge carriers into their planar structure, and prolonging their lifetime [19].

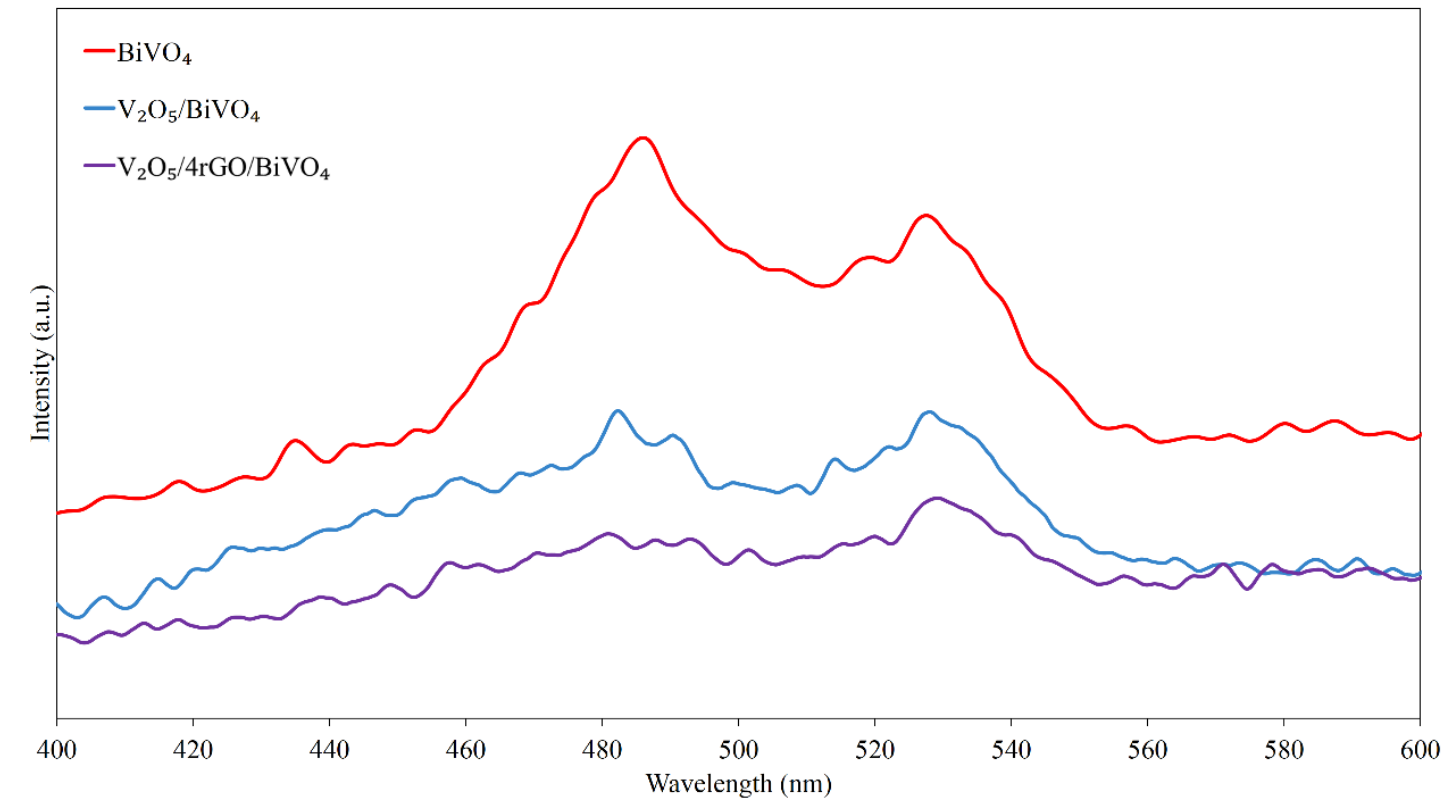

Fig. 8. PL spectrum of $\mathrm{BiVO}_{4}, \mathrm{~V}_{2} \mathrm{O}_{5} / \mathrm{BiVO}_{4}$ and $\mathrm{V}_{2} \mathrm{O}_{5} / \mathrm{rGO} / \mathrm{BiVO}_{4}$ photoanodes.

Electrochemical impedance spectroscopy (EIS) measurements were carried out for pristine $\mathrm{BiVO}_{4}$ and $\mathrm{V}_{2} \mathrm{O}_{5} / \mathrm{rGO} / \mathrm{BiVO}_{4}$ photoanodes under $\mathrm{AM} 1.5$ solar illumination, and the results that are fitted with the Randles circuit model are shown in Fig. 9 (a). In this instance, $R_{s}$ is the solution resistance and $\mathrm{R}_{\mathrm{ct}}$ is the charge transfer resistance between the semiconductor/electrolyte interface [19, 31]. The incorporation of an $\mathrm{rGO}$ interlayer has remarkably reduced $\mathrm{R}_{\mathrm{ct}}$ from $1948.8 \Omega$ to $224.77 \Omega$. Generally, it is well accepted that the $R_{c t}$ is important electrochemical 
parameters for total series resistance of the measured photoanode where they could be served as direct indicators for its PEC performance. A significantly reduced $\mathrm{R}_{\mathrm{ct}}$ implies that the rGO interlayer provides an efficient pathway for photogenerated charge carriers extraction from $\mathrm{BiVO}_{4}$ to $\mathrm{V}_{2} \mathrm{O}_{5}$ with a lower interfacial charge recombination. Additionally, the intensity modulated photocurrent spectroscopy (IMPS) was employed as a complementary technique to understand the chemical physics surrounding the separation, transport and recombination processes of photogenerated charge carriers at the semiconductor/electrolyte interface $[32,33]$. For this IMPS measurement, an AC perturbation of light intensity was superimposed on illumination of the photoanode at a constant applied potential while the periodic photocurrent response of the photoanode was reported as a function of modulation frequency. Fig. S1 and S2 show the typical IMPS responses for pristine $\mathrm{BiVO}_{4}$ and $\mathrm{V}_{2} \mathrm{O}_{5} / \mathrm{rGO} / \mathrm{BiVO}_{4}$ in the complex plane plot over a range of applied potential (V), respectively. In this instance, the IMPS responses are represented by semicircles with different radii at different applied potentials. It is expected that the low frequency intercept (i.e. recombination semicircle) increases with increasing applied potential, and this represents the fraction of photogenerated holes that arrives at the semiconductor interface before being injected into the electrolyte. Whilst the semicircle observed in the high frequency quadrant provides information on the recombination of charge transfer and relaxation inside the photoanode.

When compared to pristine $\mathrm{BiVO}_{4}$, the semicircles for the ternary $\mathrm{V}_{2} \mathrm{O}_{5} / \mathrm{rGO} / \mathrm{BiVO}_{4}$ in the low frequency quadrant was restricted and this observation reaffirmed the role of rGO interlayer in enhancing the separation efficiency of photogenerated charges carriers. From the IMPS analysis, the maximum imaginary corresponds to the sum of the charge transfer $\left(\mathrm{K}_{\mathrm{t}}\right)$ and recombination $\left(\mathrm{K}_{\mathrm{r}}\right)$ rate constants $\left(K_{r}+K_{t}=2 \pi f_{\text {max }}\right)$. Additionally, the ratio of the low and high frequency intercepts equal to the charge transfer efficiency $\left(\frac{K_{t}}{K_{r}+K_{t}}\right)$ [34]. Fig. 9 (b) shows $K_{r}$ for pristine $\mathrm{BiVO}_{4}$ and $\mathrm{V}_{2} \mathrm{O}_{5} / \mathrm{rGO} / \mathrm{BiVO}_{4}$ deduced from the IMPS analysis. Based on the estimated rate constants for pristine $\mathrm{BiVO}_{4}$, it was evidenced that its PEC performance was severely hindered by the charge recombination process on the photoanode surface due to the large $\mathrm{K}_{\mathrm{r}}$ value. It was noted that the $\mathrm{K}_{\mathrm{r}}$ was reduced by $98.9 \%$ with the formation of heterojunction between $\mathrm{BiVO}_{4}$ and $\mathrm{V}_{2} \mathrm{O}_{5}$, and incorporation of an $\mathrm{rGO}$ interlayer. The reduction in the $\mathrm{K}_{\mathrm{r}}$ value is due to the formation of heterojunction between $\mathrm{BiVO}_{4}$ and $\mathrm{V}_{2} \mathrm{O}_{5}$ and introduction of an $\mathrm{rGO}$ interlayer that 
effectively shuttle the photogenerated electrons and led to a prolonged separation of electronhole pairs. Fig. 9 (c) shows the ratio of $\mathrm{K}_{t} / \mathrm{K}_{\mathrm{r}}$ for pristine $\mathrm{BiVO}_{4}$ and $\mathrm{V}_{2} \mathrm{O}_{5} / \mathrm{rGO} / \mathrm{BiVO}_{4}$ photoanodes, and their ratios are plotted and compared for the charge transfer efficiency. In this instance, it can be observed that the $\mathrm{K}_{t} / \mathrm{K}_{\mathrm{r}}$ ratio for $\mathrm{V}_{2} \mathrm{O}_{5} / \mathrm{rGO} / \mathrm{BiVO}_{4}$ was 8 -fold higher than that of pristine $\mathrm{BiVO}_{4}$ at the applied potential of $1.2 \mathrm{~V}$. This indicates that more photogenerated charge carriers are transferred and subsequently used for the PEC water oxidation reaction.
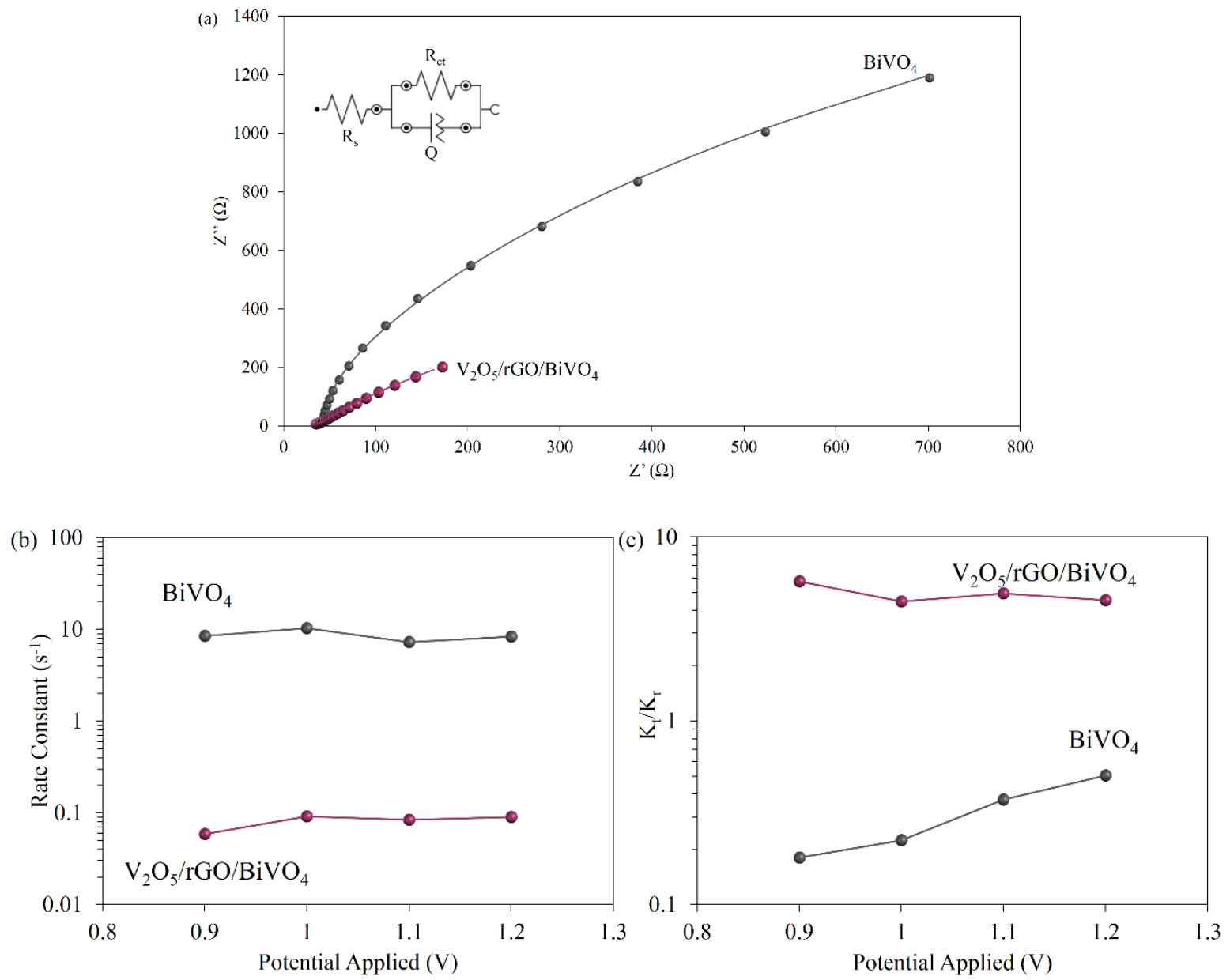

Fig. 9. Electrochemical characteristics of the photoanodes. (a) EIS Nyquist plot in $0.5 \mathrm{M}$

$\mathrm{Na}_{2} \mathrm{SO}_{4}$. IMPS responses (b) Surface recombination $\left(\mathrm{K}_{\mathrm{r}}\right)$ of pristine $\mathrm{BiVO}_{4}$ and $\mathrm{V}_{2} \mathrm{O}_{5} / \mathrm{rGO} / \mathrm{BiVO}_{4}$ and (c) rate ratio of $\mathrm{K}_{\mathrm{t}} / \mathrm{K}_{\mathrm{r}}$ for pristine $\mathrm{BiVO}_{4}$ and $\mathrm{V}_{2} \mathrm{O}_{5} / \mathrm{rGO} / \mathrm{BiVO}_{4}$ photoanodes. 
Fig. 10 shows the PEC performance of pristine $\mathrm{BiVO}_{4}$, pristine $\mathrm{V}_{2} \mathrm{O}_{5}$ and $\mathrm{GO}$ supported $\mathrm{V}_{2} \mathrm{O}_{5} / \mathrm{BiVO}_{4}$ and $\mathrm{V}_{2} \mathrm{O}_{5} / \mathrm{rGO} / \mathrm{BiVO}_{4}$ photoanode with different amount of drop-casted $\mathrm{rGO}$ in a $0.5 \mathrm{M} \mathrm{Na}_{2} \mathrm{SO}_{4}$ aqueous solution. As the potential swept towards the positive direction, anodic photocurrents were evidenced which indicated that both the pristine $\mathrm{BiVO}_{4}$ and $\mathrm{V}_{2} \mathrm{O}_{5}$ exhibited the $n$-type semiconductor behavior. The photocurrent density for the GO-coated $\mathrm{V}_{2} \mathrm{O}_{5} / \mathrm{BiVO}_{4}$ heterojunction photoanode was measured to be $0.68 \mathrm{~mA} / \mathrm{cm}^{2}$ at $1.5 \mathrm{~V}$ vs. $\mathrm{Ag} / \mathrm{AgCl}$ under $\mathrm{AM}$ 1.5 G solar light irradiation, which was much higher than its two pristine predecessors. Furthermore, the PEC performance for $\mathrm{V}_{2} \mathrm{O}_{5} / \mathrm{rGO} / \mathrm{BiVO}_{4}$ with tunable $\mathrm{rGO}$ interlayer was also being measured and systematically assessed. All the $\mathrm{V}_{2} \mathrm{O}_{5} / \mathrm{i}-\mathrm{rGO} / \mathrm{BiVO}_{4}$ heterojunction photoanodes $(i=2-5)$ with tunable rGO interlayer showed improvement in terms of their photocurrent densities. The improvement in photocurrent density is ascribed to the superior electron collection, transportation characteristic of $\mathrm{rGO}$ and the formation of the $\mathrm{C}$-Bi bond that can efficiently inhibit the recombination of photogenerated charge carriers in the proven $\mathrm{V}_{2} \mathrm{O}_{5} / \mathrm{BiVO}_{4}$ heterojunction photoanode. Among the $\mathrm{V}_{2} \mathrm{O}_{5} /$ i-rGO/BiVO 4 heterojunction photoanodes, the highest photocurrent density of $2.1 \mathrm{~mA} / \mathrm{cm}^{2}$ at $1.5 \mathrm{~V}$ vs. $\mathrm{Ag} / \mathrm{AgCl}$ was achieved when the tunable volume of rGO interlayer was $\mathrm{i}=4$ (which was $320 \mu \mathrm{L}$ ). The improvement in photocurrent density was equivalent to 3.5-fold when the PEC performance of $\mathrm{V}_{2} \mathrm{O}_{5} / 4 \mathrm{rGO} / \mathrm{BiVO}_{4}$ was benchmarked against the bare $\mathrm{V}_{2} \mathrm{O}_{5} / \mathrm{BiVO}_{4}$ heterojunction photoanode. However, it was found through experiments that any further increase in the tunable volume of rGO interlayer was detrimental to the PEC performance of the ternary heterojunction structure and resulted in low photocurrent density. This could be potentially due to the light shielding effect as imposed by the excessive use of tunable volume of rGO that eventually reduce the photon activation for the semiconductor-based heterojunction photoanode as well as the presence of physical cracks that was also observed. 


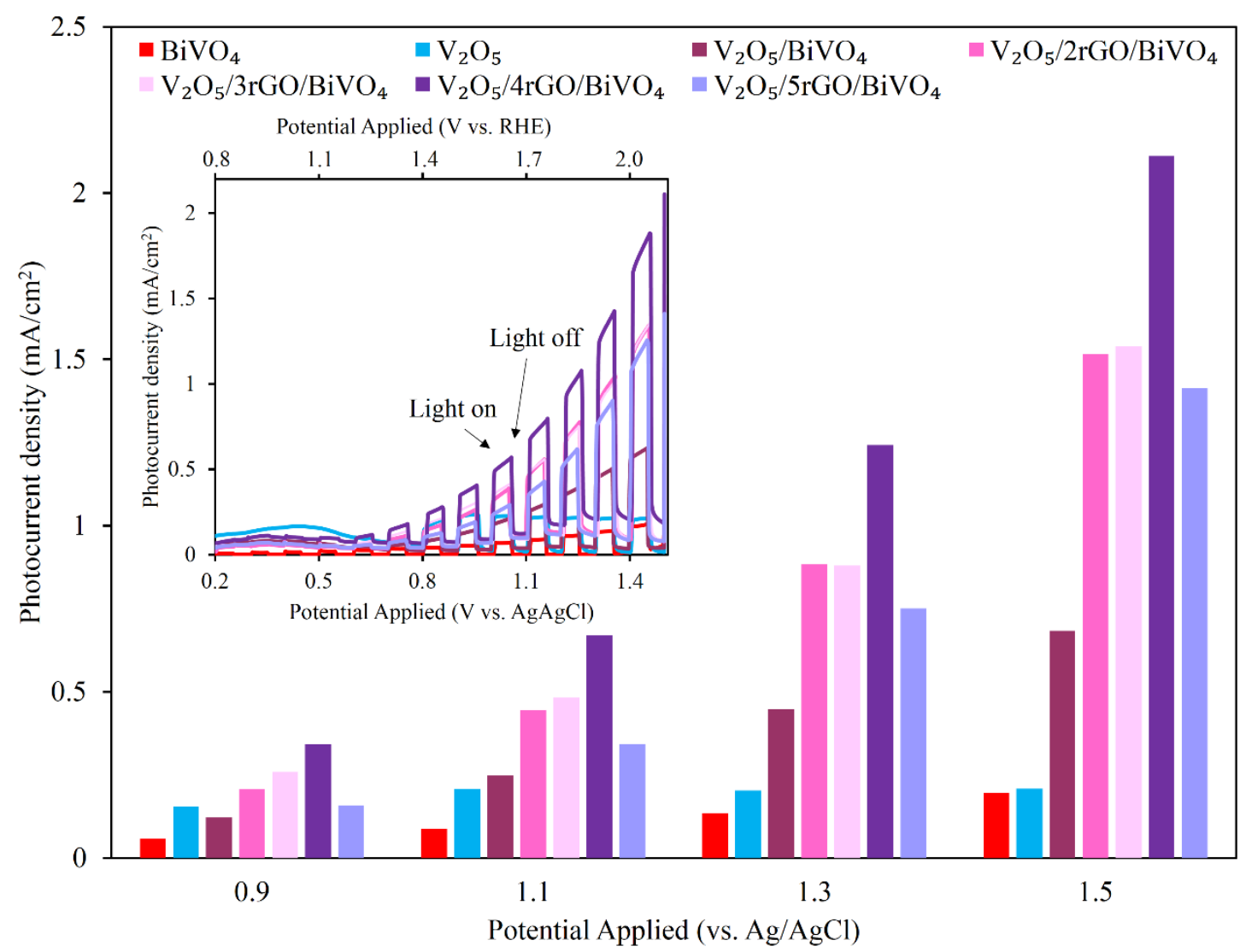

Fig. 10. Photocurrent density measured at different applied potentials of pristine $\mathrm{BiVO}_{4}$, pristine $\mathrm{V}_{2} \mathrm{O}_{5}$ and $\mathrm{GO}$ supported $\mathrm{V}_{2} \mathrm{O}_{5} / \mathrm{BiVO}_{4}$ and $\mathrm{V}_{2} \mathrm{O}_{5} / \mathrm{rGO} / \mathrm{BiVO}_{4}$ photoanode with different amount of drop-casted rGO. The inset is the photocurrent density $\left(\mathrm{mA} / \mathrm{cm}^{2}\right)$ versus potential ( $\mathrm{V}$ vs $\mathrm{Ag} / \mathrm{AgCl})$ curves.

Ultimately, the PEC water splitting activity towards $\mathrm{H}_{2}$ evolution was evaluated for both the $\mathrm{V}_{2} \mathrm{O}_{5} / \mathrm{BiVO}_{4}$ and $\mathrm{V}_{2} \mathrm{O}_{5} / 4 \mathrm{rGO} / \mathrm{BiVO}_{4}$ heterojunction photoanodes. In this study, the pristine $\mathrm{BiVO}_{4}$ photoanode cannot produce $\mathrm{H}_{2}$ correlated to the low photoactivity (i.e. photocurrent generation potential of $0.2 \mathrm{~mA} / \mathrm{cm}^{2}$ ) on its surfaces when irradiated with AM $1.5 \mathrm{G}$ solar simulated light as well as the severe electron hole recombination rate as proven by IMPS. As a result shown in Fig. 11, the $\mathrm{H}_{2}$ evolution for $\mathrm{V}_{2} \mathrm{O}_{5} / \mathrm{BiVO}_{4}$ heterojunction photoanode was $8.2 \mu \mathrm{mol} / \mathrm{hr}$ and $32.7 \mu \mathrm{mol} / \mathrm{hr}$ for the ternary $\mathrm{V}_{2} \mathrm{O}_{5} / \mathrm{rGO} / \mathrm{BiVO}_{4}$ heterojunction photoanode. This improvement is attributed to the incorporation of an interlayer of rGO in between $\mathrm{V}_{2} \mathrm{O}_{5} / \mathrm{BiVO}_{4}$ heterojunction photoanode to serve as an electron mediator for transporting electrons to prolong the lifetime of the photogenerated charge carriers. 


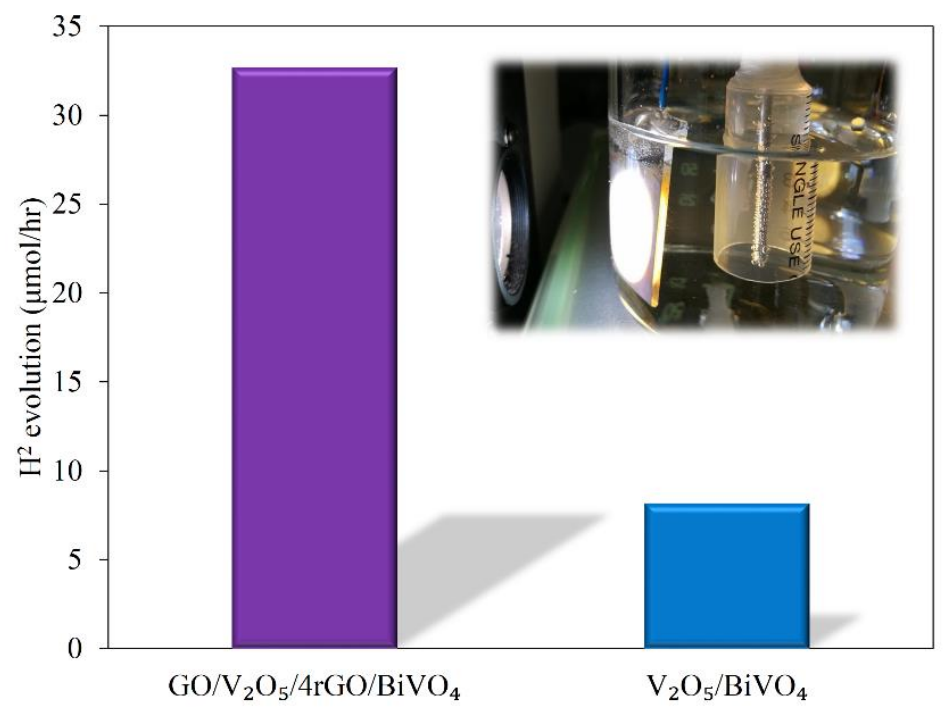

Fig. 11. $\mathrm{H}_{2}$ evolution from $\mathrm{V}_{2} \mathrm{O}_{5} / \mathrm{BiVO}_{4}$ and $\mathrm{V}_{2} \mathrm{O}_{5} / 4 \mathrm{rGO} / \mathrm{BiVO}_{4}$ photoanode. The inset is the experimental set-up for $\mathrm{H}_{2}$ evolution.

Based on the above results, a possible electron transfer mechanism for PEC water splitting is delineated in Fig. 12. Upon irradiation for the ternary $\mathrm{V}_{2} \mathrm{O}_{5} / \mathrm{rGO} / \mathrm{BiVO}_{4}$ heterojunction photoanode, the photogenerated charge carriers will be generated in the conduction and valance band of $\mathrm{BiVO}_{4}$ and $\mathrm{V}_{2} \mathrm{O}_{5}$, respectively. The rGO interlayer does not contribute to the generation of photogenerated charge carriers due to its zero energy band property. In this work, rGO behaves as an electron mediator by interfacially extract and transfer the photogenerated electrons from conduction band of $\mathrm{BiVO}_{4}$ to the conduction band of $\mathrm{V}_{2} \mathrm{O}_{5}$ and then flow to the FTO substrate. Under the external electrostatic field, accumulated photogenerated electrons will transfer to the $\mathrm{Pt}$ electrode and reduce $\mathrm{H}^{+}$ions to produce $\mathrm{H}_{2}$ molecules. Concurrently, the photogenerated holes at the valance band of $\mathrm{V}_{2} \mathrm{O}_{5}$ will transfer and accumulate at the valance band of $\mathrm{BiVO}_{4}$ via the rGO interlayer [35]. The accumulated photogenerated holes in the $\mathrm{BiVO}_{4}$ will react with $\mathrm{O}^{2-}$ ions to generate oxygen molecules. In overall, the incorporation of rGO can enhance the separation of the photogenerated charge carriers which is the crucial for the improvement of PEC water splitting efficiency. 


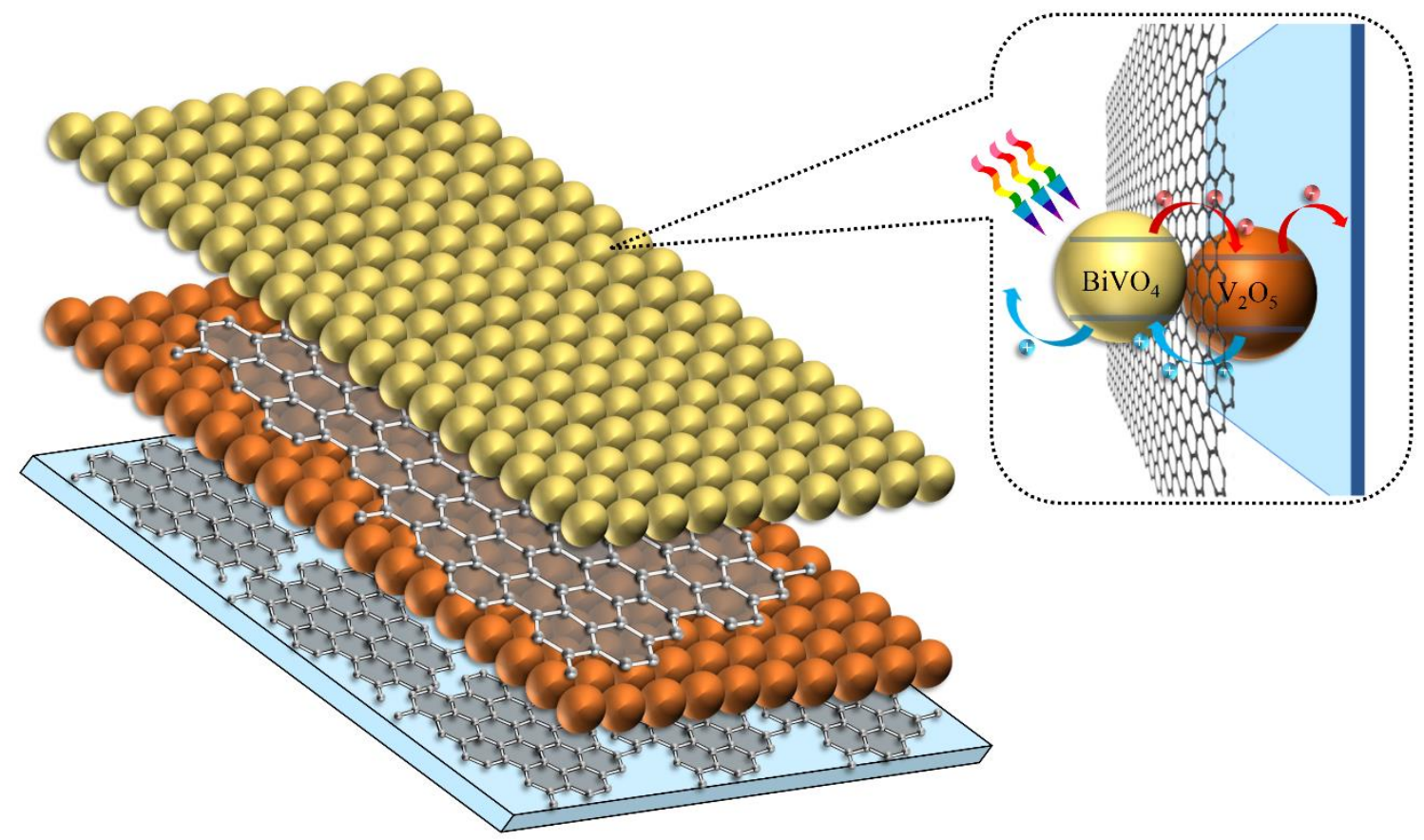

Fig. 12. Schematic of electron transfer mechanism in $\mathrm{V}_{2} \mathrm{O}_{5} / \mathrm{rGO} / \mathrm{BiVO}_{4}$ heterojunction photoanode for PEC water splitting.

\section{Conclusion}

To conclude, we have designed and validated a novel $\mathrm{V}_{2} \mathrm{O}_{5} / \mathrm{rGO} / \mathrm{BiVO}_{4}$ heterojunction photoanode. The incorporation of an efficient charge transport medium- rGO interlayer in between a proven $\mathrm{V}_{2} \mathrm{O}_{5} / \mathrm{BiVO}_{4}$ heterojunction photoanode has improved light harvesting efficiency and electronic transmission performance across the $\mathrm{V}_{2} \mathrm{O}_{5} / \mathrm{BiVO}_{4}$ that can be inhibit the recombination rate of electron-hole pairs. Therefore, the tunable amount of drop-casted rGO interlayer has an effect on the eventual photocurrent density generation potential. Among the asprepared samples, the ternary $\mathrm{V}_{2} \mathrm{O}_{5} / \mathrm{i}-\mathrm{rGO} / \mathrm{BiVO}_{4}(\mathrm{i}=4)$ heterojunction photoanode exhibited the highest photocurrent density of $2.1 \mathrm{~mA} / \mathrm{cm}^{2}$ at $1.5 \mathrm{~V}$ vs. $\mathrm{Ag} / \mathrm{AgCl}$ which was approximately 9.7 times more photoactive than the pristine $\mathrm{BiVO}_{4}$. Furthermore, the $\mathrm{H}_{2}$ evolution rate further confirmed the enhanced efficiency of ternary nanostructured $\mathrm{V}_{2} \mathrm{O}_{5} / \mathrm{rGO} / \mathrm{BiVO}_{4}$ heterojunction photoanode. Hence, the alignment of energy bands and trap states of the $\mathrm{BiVO}_{4}$ (sensitiser), $\mathrm{rGO}$ (electron transporter) and $\mathrm{V}_{2} \mathrm{O}_{5}$ (electron acceptor) is the vital in governing the shuttling of photogenerated charge carriers between the semiconductors. 


\section{Supporting Information}

Intensity-modulated photocurrent spectroscopy (IMPS) responses of pristine $\mathrm{BiVO}_{4}$ (Fig. S1) and $\mathrm{V}_{2} \mathrm{O}_{5} / \mathrm{rGO} / \mathrm{BiVO}_{4}$ photoanode (Fig. S2).

\section{Acknowledgement}

Prof. MN Chong is highly indebted to the Royal Society-Newton Advanced Fellowship (Reference No.: NA150418) awarded to him in collaboration with Prof. J Tang at the University College London (UCL) Solar Energy \& Advanced Materials group.

\section{Reference}

[1] M.N. Chong, A.N.M. Ho, T. Gardner, A.K. Sharma, B. Hood, Assessing Decentralised Wastewater Treatment Technologies: Correlating Technology Selection to System Robustness, Energy Consumption and GHG Emission, J. Water Clim. Change 4 (2013) 338-347.

[2] Y.W. Phuan, W-J. Ong, M.N. Chong, J.D. Ocon, Prospects of Electrochemically Synthesized Hematite Photoanodes for Photoelectrochemical Water Splitting: A Review, J. Photochem. Photobiol. C 33 (2017) 54-82.

[3] T. Zhu, M. N. Chong, E. S. Chan, J.D. Ocon, Synthesis And Characterisation of A Novel Bilayer Tungsten Trioxide Nanojunction With Different Crystal Growth Orientation for Improved Photoactivity Under Visible Light Irradiation, J. Alloys Compd. 749 (2018) 268-275.

[4] T. Zhu, M. N. Chong, E. S. Chan, J.D. Ocon, Electrochemically-Synthesized Tungstate Nanocomposites $\gamma-\mathrm{WO}_{3} / \mathrm{CuWO}_{4}$ and $\gamma-\mathrm{WO}_{3} / \mathrm{NiWO}_{4}$ Thin Films With Improved Band Gap and Photoactivity for Solar-Driven Photoelectrochemical Water Oxidation, J. Alloys Compd. 762 (2018) 90-97.

[5] Y. W. Phuan, M. N. Chong, K. Egamparan, B-K. Lee, T. Zhu, E. S. Chan, Understanding The Synergistic Between Optimum Dopant Loading and Charge Transfer Kinetics In PlatinumMediated Nanostructured Hematite Thin Films, J. Taiwan Inst. Chem. Eng. 66 (2016) 249-257. 
[6] W. Fan, X. Yu, H-C. Lu, H. Bai, C. Zhang, W. Shi, Fabrication of $\mathrm{TiO}_{2} / \mathrm{RGO} / \mathrm{Cu}_{2} \mathrm{O}$ Heterostructure for Photoelectrochemical Hydrogen Production, Appl. Catal. B 181 (2016) 7-15.

[7] W. Sun, D. Wang, Z.U. Rahman, N. Wei, S. Chen, 3D Hierarchical $\mathrm{WO}_{3}$ Grown on $\mathrm{TiO}_{2}$ Nanotube Arrays and Their Photoelectrochemical Performance for Water Splitting, J. Alloys Compd. 695 (2017)

[8] I. Fujishima, K. Honda, Photoelectrolysis of Water Using Titanium Oxide, Nature 238 (1972) 38.

[9] A. Paracchino, V, Laporte, K. Sivula, M. Grätzel, E. Thimsen, Highly Active Oxide Photocathode For Photoelectrochemical Water Reduction, Nat. Mater. 10 (2011) 456-461.

[10] C. Li, W. Fan, H. Lu, Y. Ge, H. Bai, W. Shi, Fabrication of Au@CdS/RGO/TiO Heterostructure For Photoelectrochemical Hydrogen Production, New J. Chem. 40 (2016) 22872295.

[11] J.A. Seabold, K-S. Choi, Efficient and Stable Photo-Oxidation of Water by A Bismuth Vanadate Photoanode Coupled with An Iron Oxyhydroxide Oxygen Evolution Catalyst, J. Am. Chem. Soc. 134 (2012) 2186-2192.

[12] B. Pattengale, J. Ludwig, J. Huang, Atomic Insight Into The W-Doping Effect On Carrier Dynamics and Photoelectrochemical Properties of $\mathrm{BiVO}_{4}$ Photoanodes, J. Phys. Chem. C 120 (2016) 1421-1427.

[13] A.P. Singh, N. Kodan, B.R. Mehta, A. Held, L. Mayrhofer, M. Moseler, Band Edge Engineering in $\mathrm{BiVO}_{4} / \mathrm{TiO}_{2}$ Heterostructure: Enhanced Photoelectrochemical Performance through Improved Charge Transfer, ACS Catal. 6 (2016) 5311-5318.

[14] W. Sun, S. Cui, N. Wei, S. Chen, Y. Liu, D. Wang, Hierarchical $\mathrm{WO}_{3} / \mathrm{TiO}_{2}$ Nanotube Nanocomposites for Efficient Photocathodic Protection of 304 Stainless Steel Under Visible Light, J. Alloys Compd. 749 (2018) 741-749.

[15] C.S. Yaw, Q. Ruan, J. Tang, A.K.Soh, M.N. Chong, A Type II n-n Staggered Orthorhombic $\mathrm{V}_{2} \mathrm{O}_{5} /$ Monoclinic Clinobisvanite $\mathrm{BiVO}_{4}$ Heterojunction Photoanode for 
Photoelectrochemical Water Oxidation: Fabrication, Characterisation and Experimental Validation, Chem. Eng. Sci. 364 (2019) 177-185.

[16] F. Chen, Q. Yang, Y. Zhong. H. An, J. Zhao, T. Xie, Q. Xu, X. Li, D. Wang, G. Zeng, Photo-Reduction of Bromate in Drinking Water by Metallic Ag and Reduced Graphene Oxide (RGO) Jointly Modified $\mathrm{BiVO}_{4}$ Under Visible Light Irradiation, Water Res. 101 (2016) 555-563.

[17] H.L. Tan, H.A. Tahini, X. Wen, R.J. Wong, X. Tan, A. Iwase, A. Kudo, R. Amal, S.C. Smith, Y.H. Ng, Interfacing $\mathrm{BiVO}_{4}$ with Reduced Graphene Oxide for Enhanced Photoactivity: A Tale of Facet Dependence of Electron Shuttling, Small 12 (2016) 5295-5302.

[18] K. Zhao, X. Yan, Y. Gu, Z. Kang, Z. Bao, S. Cao, Y. Liu, X. Zhang, Y. Zhang, SelfPowered Photoelectrochemical Biosensor Based on $\mathrm{CdS} / \mathrm{RGO} / \mathrm{ZnO}$ Nanowire Array Heterostructurec Small 12 (2016) 245-251.

[19] Y. Phuan, M.N. Chong, T. Zhu, E.S. Chan, J.D. Ocon, Employing Electrochemical Reduced Graphene Oxide as A Co-Catalyst For Synergistically Improving The Photoelectrochemical Performance of Nanostructured Hematite Thin Films, J. Taiwan Inst. Chem. Eng. 71 (2017) 510-517.

[20] L. Gao, J. Xie, X. Ma, M. Li, L. Yu, DNA@ $\mathrm{Mn}_{3}\left(\mathrm{PO}_{4}\right)_{2}$ Nanoparticles Supported with Graphene Oxide as Photoelectrodes for Photoeletrocatalysis, Nanoscale Res. Lett. 12 (2017) 17.

[21] S.M. Ho-Kimura, S.J.A. Moniz, A.D. Handoko, Enhanced Photoelectrochemical Water Splitting by Nanostructured $\mathrm{BiVO}_{4}-\mathrm{TiO}_{2}$ Composite Electrodes, J. Mater. Chem. A 2 (2014) 3948-3953.

[22] Y. Phuan, M.N. Chong, T. Zhu, J.D. Ocon, E.S. Chan, A Novel Ternary Nanostructured Carbonaceous-Metal-Semiconductor eRGO/NiO/ $\alpha-\mathrm{Fe}_{2} \mathrm{O}_{3}$ Heterojunction Photoanode With Enhanced Charge Transfer Properties for Photoelectrochemical Water Splitting, Sol. Energy Mater. Sol. Cells 169 (2017) 236-244.

[23] J. Yu, J. Jin, B. Cheng, M. Jaroniec, A Noble Metal-Free Reduced Graphene Oxide-CdS Nanorod Composite for The Enhanced Visible-Light Photocatalytic Reduction Of $\mathrm{CO}_{2}$ To Solar Fuel, J. Mater. Chem. A 2 (2014) 3407-3416. 
[24] C. Nithya, S. Gopukumar, rGO/nano Sb composite: A High Performance Anode Material for $\mathrm{Na}^{+}$Ion Batteries and Evidence for The Formation of Nanoribbons From The Nano Rgo Sheet During Galvanostatic Cycling, J. Mater. Chem. A 2 (2014) 10516-10525.

[25] K. Takahashi, S.J. Limmer, Y. Wang, G. Cao, Growth And Electrochemical Properties Of Single-Crystalline $\mathrm{V}_{2} \mathrm{O}_{5}$ Nanorod Arrays, Jpn. J. Appl. Phys. 44 (2005) 662.

[26] L. Yan, W. Zhao, Z. Liu, 1D ZnO/Bivo4 Heterojunction Photoanodes for Efficient Photoelectrochemical Water Splitting, Dalton Trans. 45 (2016) 11346-11352.

[27] A. Galembeck, O. Alves, $\mathrm{BiVO}_{4}$ Thin Film Preparation by Metalorganic Decomposition, Thin Solid Films 365 (2000) 90-93.

[28] Y. Li, H. Zhang, P. Liu, D. Wang, Y. Li, H. Zhao, Cross-Linked g- $\mathrm{C}_{3} \mathrm{~N}_{4} / \mathrm{rGO}$ Nanocomposites with Tunable Band Structure and Enhanced Visible Light Photocatalytic Activity, Small 9 (2013) 3336-3344.

[29] Y.W. Phuan, E. Ibrahim, M.N. Chong, T. Zhu, B-K. Lee, J.D. Ocon, E.S. Chan, In situ Ni-doping During Cathodic Electrodeposition Of Hematite For Excellent Photoelectrochemical Performance Of Nanostructured Nickel Oxide-Hematite pn Junction Photoanode, Appl. Surf. Sci. 392 (2017) 144-152.

[30] C. Karunakaran, S. Kalaivani, P. Vinayahamoorthy, S. Dash, Electrical, Optical And Visible Light-Photocatalytic Properties Of Monoclinic $\mathrm{BiVO}_{4}$ Nanoparticles Synthesized Hydrothermally At Different pH, Mater. Sci. Semicond. Process. 21 (2014) 122-131.

[31] J.K. Kim, X. Shi, M.J. Jeong, J. Park, H.S. Han, S.H. Kim, Y. Guo, S. Fan, C-L. Lee, Enhancing Mo:BiVO 4 Solar Water Splitting with Patterned Au Nanospheres by PlasmonInduced Energy Transfer, Adv, Energy Mater. 8 (2017) 1701765.

[32] L.M. Peter, K.U. Wijayantha, A.A. Tahir, Kinetics Of Light-Driven Oxygen Evolution at $\alpha-\mathrm{Fe}_{2} \mathrm{O}_{3}$ Electrodes, Faraday Discuss. 155 (2012) 309-322.

[33] Q. Ruan, W. Luo, J. Xia, Y. Wang, X. Liu, Z. Bai, C.J. Carmalt, J. Tang, A Nanojunction Polymer Photoelectrode for Efficient Charge Transport and Separation, Angew. Chem. 56 (2017) 8221-8225. 
[34] C.Y. Cummings, F. Marken, L.M. Peter, A.A. Tahirm, K.G.U. Wijayantha, Kinetics and Mechanism of Light-Driven Oxygen Evolution at Thin Film $\alpha-\mathrm{Fe}_{2} \mathrm{O}_{3}$ Electrodes, Chem. Comm. 48 (2012) 2027-2029.

[35] G. Konstantatos, M. Badioli, L. Gaudreau, J. Osmond, M. Bernechea, F.P.G. De Arquer, F. Gatti, F.H.L. Koppens, Hybrid Graphene-Quantum Dot Phototransistors with Ultrahigh Gain, Nat. nanotechnol. 7 (2012) 363-368.

\section{Supporting Information}

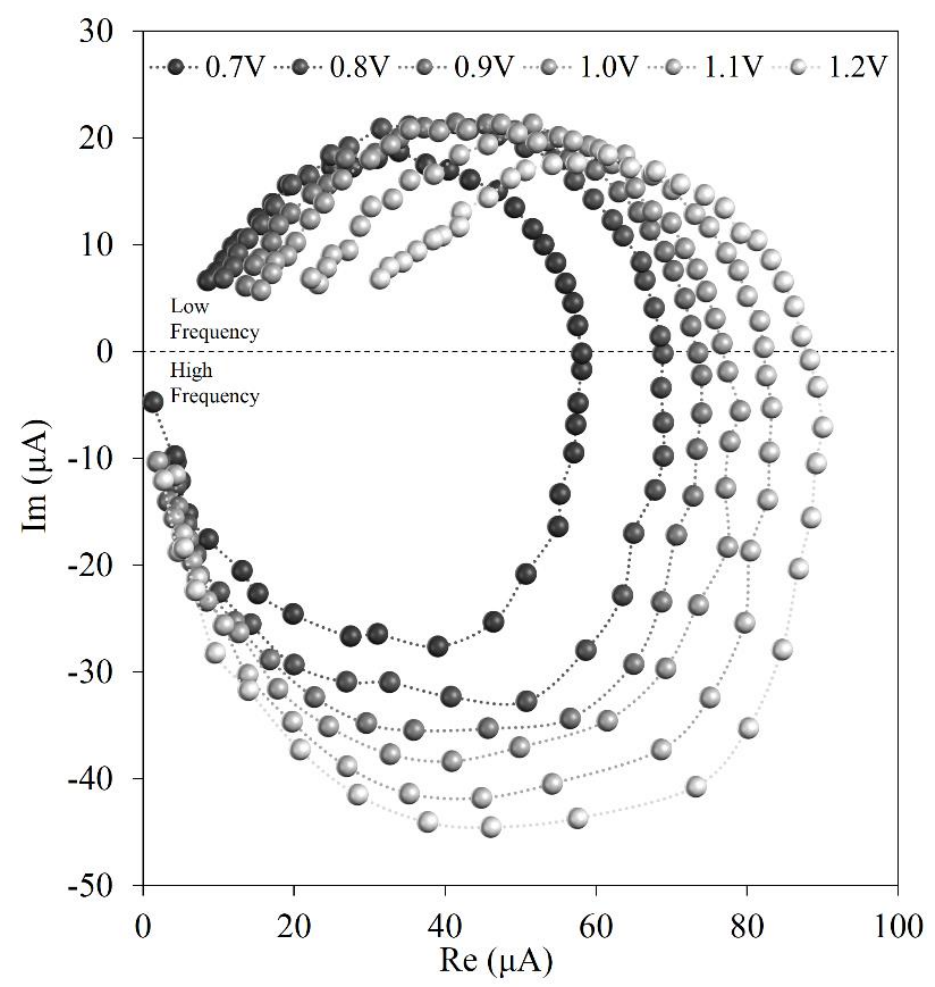

Fig. S1. Intensity-modulated photocurrent spectroscopy (IMPS) responses of pristine $\mathrm{BiVO}_{4}$ photoanode. 


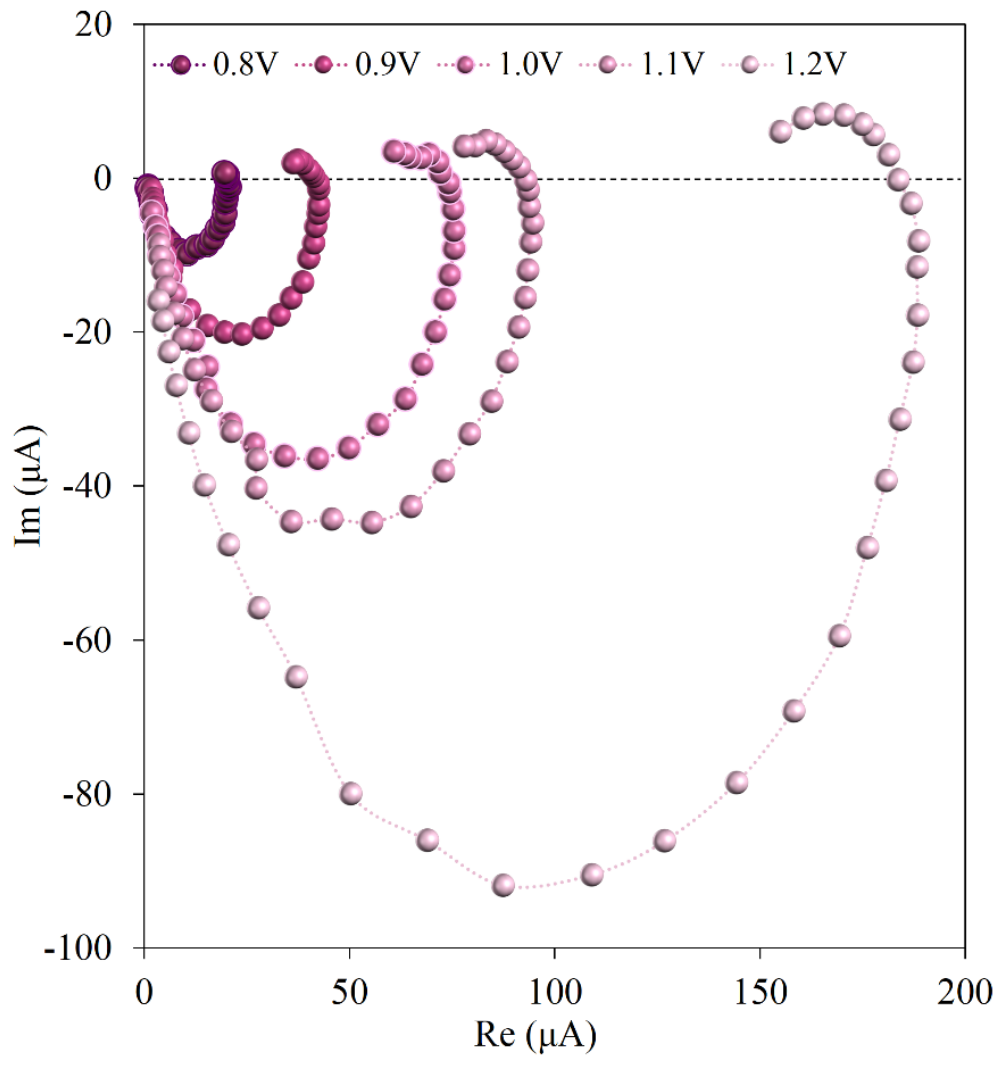

Fig. S2. Intensity-modulated photocurrent spectroscopy (IMPS) responses of pristine $\mathrm{V}_{2} \mathrm{O}_{5} / \mathrm{rGO} / \mathrm{BiVO}_{4}$ photoanode. 